\title{
Non-invasive imaging methods applied to neo- and paleo-ontological cephalopod research
}

\author{
R. Hoffmann ${ }^{1}$, J. A. Schultz ${ }^{2}$, R. Schellhorn ${ }^{2}$, E. Rybacki ${ }^{3}$, H. Keupp ${ }^{4}$, S. R. Gerden ${ }^{1}$, R. Lemanis ${ }^{1}$, and S. Zachow ${ }^{5}$ \\ ${ }^{1}$ Institut für Geologie, Mineralogie und Geophysik, Ruhr Universität Bochum, Universitätsstrasse 150, 44801 Bochum, \\ Germany \\ ${ }^{2}$ Steinmann-Institut für Geologie, Mineralogie und Paläontologie, Rheinische Friedrich-Wilhelms-Universität Bonn, \\ Nussallee 8, 53115 Bonn, Germany \\ ${ }^{3}$ Helmholtz-Zentrum Potsdam, Deutsches GeoForschungsZentrum GFZ Sektion 3.2, Geomechanik und Rheologie, \\ Telegrafenberg, D 429, 14473 Potsdam, Germany \\ ${ }^{4}$ Institut für Geologische Wissenschaften, Fachrichtung Paläontologie, Freie Universität Berlin, Malteserstrasse 74-100, \\ 12249 Berlin, Germany \\ ${ }^{5}$ Zuse Institut Berlin, Takustrasse 7, 14195 Berlin, Germany \\ Correspondence to: R. Hoffmann (rene.hoffmann@rub.de)
}

Received: 28 October 2013 - Published in Biogeosciences Discuss.: 29 November 2013

Revised: 14 March 2014 - Accepted: 29 March 2014 - Published: 22 May 2014

\begin{abstract}
Several non-invasive methods are common practice in natural sciences today. Here we present how they can be applied and contribute to current topics in cephalopod (paleo-) biology. Different methods will be compared in terms of time necessary to acquire the data, amount of data, accuracy/resolution, minimum/maximum size of objects that can be studied, the degree of post-processing needed and availability. The main application of the methods is seen in morphometry and volumetry of cephalopod shells. In particular we present a method for precise buoyancy calculation. Therefore, cephalopod shells were scanned together with different reference bodies, an approach developed in medical sciences. It is necessary to know the volume of the reference bodies, which should have similar absorption properties like the object of interest. Exact volumes can be obtained from surface scanning. Depending on the dimensions of the study object different computed tomography techniques were applied.
\end{abstract}

\section{Introduction}

During the last decade non-invasive diagnostics has become increasingly important for paleontological research. The analysis of shapes of fossil hard parts, either fully or par- tially preserved within the surrounding rocks, requires imaging methods that are primarily used in non-destructive testing. The conservation of the specimen is of main importance using these methods since former techniques used destructive methods leading to the loss of the specimen or parts of the specimen. Enhanced tomographic imaging techniques enable a view inside solid objects with astonishing spatial resolution. Typical tasks for the reconstruction of structures from tomographic image data are digital image processing (like filtering and enhancement), segmentation (e.g., classification), and geometry processing.

The oldest record of the application of non-invasive methods in the field of cephalopod research dates back to the publication of Lehmann (1932). By using x-rays Lehmann (1932) produced stereo images of a 3-D impression of the internal structures of a Lower Jurassic ammonite. A few years earlier Sollas (1904) invented a method using serial sections that allowed the visualization of internal structures of fossils. This approach has formed the basis of modern grinding tomography (e.g., Pascual-Cebrian et al., 2013). Much has been improved since the earliest attempts, invasive or not, for 3-D reconstructions of fossils and their internal structures (Sollas and Sollas, 1914; Tipper, 1976; Luo and Ketten, 1991; Herbert et al., 1995; Hurum, 1996; Stock, 2006; Tafforeau et al., 2006; Sutton et al., 2001, 
Hoffmann and Zachow, 2011; Falkingham, 2012). Specifically for cephalopods non-invasive methods were used lately for reconstructing internal soft parts, mainly buccal masses of ammonoids, e.g., Klug et al. (2012), Kruta et al. (2013, 2014), and Tanabe et al. (2013), and were also used on extant cephalopods, e.g., Westermann et al. (2002) and Kerbl et al. (2013). Recently, Sutton et al. (2014) published an extensive overview of techniques for virtual paleontology, including destructive and non-destructive approaches. Advantages and disadvantages of non-invasive methods (surface scanning, computed tomography, magnetic resonance tomography) tested by the authors are discussed below.

Advantages of the non-invasive approach are: external and/or internal structures of specimens can be studied in great detail in 2-D and 3-D while the specimen itself remains untouched (Fig. 1), scan data can be shared within the scientific community, used for a virtual visit of museum collections (e.g., http://www.3d-fossils.ac.uk/home.html), to maintain a record of type material that may later be destroyed or lost in the future, or can be stored for later studies to solve new questions. A clear advantage for future work is the possibility to store and share the CT data and make them available for subsequent studies of other researchers. Rare fossils (e.g., holotype material) can be duplicated as 3-D prints and sent to scientists all over the world or used for lectures (Rahman et al., 2012), exhibitions and outreach programs. Single pieces of a broken specimen can be scanned separately, merged digitally - as shown by Hoffmann (2010) for an Upper Cretaceous hollow preserved ammonite - and printed in one piece afterwards (Fig. 1b). Multiplanar reconstructions (MPR, Fig. 1a) and surface and volume renderings (Fig. 3b) can also be applied to the data sets. Presentation animations and instructive movies can be created. Finally, accurate surface models can be derived from these methods and used for advanced functional analyses such as finite element analysis (FEA), computational fluid dynamics (CFD, e.g., Shiino et al. 2012) and multibody dynamic analysis (MBD, Anderson et al., 2012; Bates and Falkingham, 2012). Because FEA is beyond the scope of this article the reader is referred to Rayfiled (2007) for a review of FEA in palaeontology. One main goal for future research should be the establishment of a 3-Dshaped database for ammonoids, comparable to the GenBank of biologists. We chose cephalopods as ideal candidates for this non-invasive method study because of their longevity, high abundance and wide distribution during Earth's history, their meaning for biostratigraphy due to high evolutionary rates, importance for tracing evolutionary mechanisms and their complex internal structure and its possible function, which was under debate for centuries. Besides measuring distances the main challenge here is to test whether the ammonoids - a group that appeared during the Devonian and went extinct at the Cretaceous-Paleogene event - could swim or not. We emphasize here that this question is moreover important for a wider scientific community interested in paleoenvironmental changes. It aims at clarifying the ques-
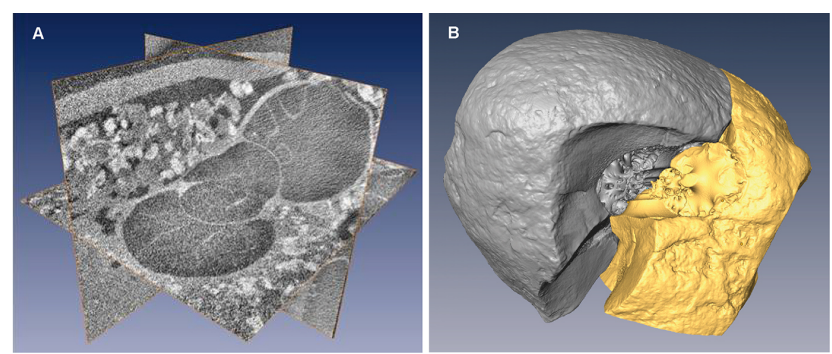

Figure 1. Multiplanar reconstructions (MPR). (A) Tomographic data set of a hollow Lower Jurassic (Toarcian) Eleganticeras (about $1 \mathrm{~cm}$ in diameter) with a size of $9 \mathrm{~GB}$, acquired with a v|tome|x s $(180 \mathrm{kV}$ tube current, res. $6 \mu \mathrm{m})$. MPR and visualization obtained with the ZIBAmira 3-D software. (B) Digitally merged data set of two separately scanned (res. $45 \mu \mathrm{m}$ ) parts of a broken Upper Cretaceous concretion of about $13 \mathrm{~cm}$ in diameter that contains one specimen of Gaudryceras sp. (about $8 \mathrm{~cm}$ in diameter, coll. Y. Shigeta, Tokyo).

tion of whether ammonoids were benthic crawlers or could freely swim in the water column, with wider implications for predator-prey relationships. It is therefore of critical importance for those interested in the interpretation of $\delta^{18} \mathrm{O}$ signatures derived from ammonoid shells, as well as for the reconstruction of the evolution of paleoenvironments. For recent constraints on ammonoid paleobiology and life history the reader is referred to Ritterbush et al. (2014).

In order to answer this question we performed the first test with the shells of the recent Nautilus and Spirula and calculated the buoyancy values for each. For both species it is well known that they were able to swim freely in the water column. Furthermore, non-invasive methods can be applied not only for volumetry but also for 2-D measurements of cephalopod shells and will contribute to the quantitative morphological approach taking intraspecific variability of species into account (Hoffmann et al. 2012).

Due to their accretionary growth, molluscs record their whole ontogeny with their shells. 2-D measurements of distances and their ontogenetic changes (ontogenetic trajectories) with a higher resolution (from $45^{\circ}$ down to $1^{\circ}$ ) compared to the cutting approach $\left(180\right.$ or $\left.90^{\circ}\right)$ increase the precision of morphological description. First 2-D measurements were performed on the micro-CT images of the extant $\mathrm{Nau}$ tilus and Spirula and afterwards on the micro-CT images of fossil ammonites following the key of description for ammonoid conchs of Korn (2010). Due to the advantages of some of the non-invasive methods we were able to add internal characters to the classical conch parameter (e.g., ammonitella length, septal angle, septal thickness profiles, septal spacing, diameter of the siphuncle at a certain conch diameter, relative position of the siphuncle, and conch wall thickness at a certain conch diameter). Only after segmentation can the CT data be analyzed for ontogenetic changes of volumes (chambers, shell) and a final buoyancy calculation. 
For each of the presented methods a potential application was provided. We developed a strategy using different noninvasive methods in order to conduct a reliability study for the calculation of precise volumes, which is necessary for subsequent buoyancy calculations, which has not been done before. To the best of our knowledge there are no studies available comparing different non-invasive methods and their potential to solve open questions in cephalopod research. As briefly described above there is a broad field of possible applications for non-invasive methods. With our contribution we hope to motivate researchers to apply more non-invasive methods in cephalopod and other invertebrate research.

\section{Material}

For comparison of the different methods we examined shells of two extant cephalopods (e.g., the deep sea squid Spirula spirula from the Canary Islands with a diameter of $1.6 \mathrm{~cm}$ (coll. R. Hoffmann, SsCI_01), and a $17 \mathrm{~cm}$ diameter Nautilus pompilius from the Philippines (coll. R. Hoffmann, $\left.\mathrm{NpPh} \_01\right)$ ). As representatives of the extinct ammonoids we examined an Eleganticeras sp. from the Lower Jurassic of Grimmen, Germany (coll. R. Hoffmann, ElGr_01), a giant Lobolytoceras costellatum from the Upper Jurassic (Oxfordian) of Madagascar (coll. H. Keupp, MAn-3059, $61.5 \mathrm{~cm}$ in diameter), three juvenile upper Middle Jurassic (Callovian) ammonites (?Cadoceras sp.) from the Kostroma region of Russia with diameters between 2 and $5 \mathrm{~mm}$ (coll. R. Hoffmann, CaKr_01, CaKr_02, CaKr_03), a Gaudryceras sp. about $5 \mathrm{~cm}$ in diameter, scanned with the surrounding concretion of about $20 \mathrm{~cm}$ (Fig. 1b) from the Upper Cretaceous (Maastrichtian) of Kamtchatka (coll. Y. Shigeta, Tokyo, without invent no.), a Craspedites sp. from the Volgian of the Kostroma region, Russia - the latter three are preserved in nearly hollow conditions, one median section of Argonauticeras sp. of $9.5 \mathrm{~cm}$ diameter, from the Lower Cretaceous (Albian) from Madagascar (coll. R. Hoffmann, ArMa_01). A single pathological rostrum of the belemnite Hibolithes jaculoides (coll. H. Keupp, PB251) from the Lower Cretaceous (Hauterivian) of Heligoland (Germany) and one calcite crystal were also examined.

\section{Methods}

\subsection{Surface scanning}

A variety of manufacturers (e.g., STEINBICHLER ${ }^{\circledR}$, BREUCKMANN $^{\circledR}$, DAVID $^{\circledR}$ ) provide products to digitize objects of different sizes and materials in a broad spectrum of resolutions and different price segments. The polygonal surface models (Fig. 2) presented here have been made with a BREUCKMANN ${ }^{\circledR}$ optoTOP-HE system (Table 1) using the optocat 2007 R3 software (v7.20.03). The used technology is a combination of phase shift and Gray code (Gray,
1953), a modified binary codification. The correct distance between object and camera/projector, and therefore constant resolution, is assured by the two laser points, which have to be congruent on the object's surface. Single scans and their alignment can be made manually, or by an optional turntable that allows an automatic alignment, at least for one side of the object. A dark room is recommended to reduce diffused light. The surface of the object should be mat finished with a special whitening spray or by coating with ammonium chloride $\left(\mathrm{NH}_{4} \mathrm{Cl}\right)$. A special mounting of the object is not needed, but it should be positioned in a stable manner to avoid movements during the scan. As long as it is possible to keep the correct distance of the sensor, scanning is possible. If the object exceeds the field of view (FOV), or not every part of the object was captured with one scan, several scans will be necessary in order to cover the whole surface or all details. For larger objects there has to be an overlap of the scanned area. It is possible to set landmarks in these overlapping areas for aligning them in one large model. All scans are then merged and overlapping areas are removed to reduce the file size afterwards. The resulting polygonal model file size depends on the used sensor and the number of single scans, but compared to the $60 \mu \mathrm{m}$ sensor the file size of the $16 \mu \mathrm{m}$ sensor is around 10 times larger. The amount of data including all sub-scan files is nearly the same in both sensors. A disadvantage of the used technology are objects with deep narrow holes or furrows, as it is difficult to project the Graycode patterns inside the holes and detect them with the camera at the same time. This leads to missing data within the polygonal model, causing holes in the surface mesh (Fig. 2). These holes can be closed during the data post-processing (e.g., with PolyWorks ${ }^{\circledR}$ ). With such post-processing software the volume of any scanned object can be calculated. The accuracy of the calculated volume depends on the resolution and geometry but is independent of the chemical composition and therefore absorption properties or density of the object, which plays an important role in computed tomography for instance (Table 2).

\subsection{Computed tomography (CT)}

Leading companies that produce medical CT scanners are NIKON $^{\circledR}$, SIEMENS $^{\circledR}$, PHILIPS $^{\circledR}$ and General Electric ${ }^{\circledR}$ $\left(\mathrm{GE}^{\circledR}\right)$ among others (Table 1). The investigated giant ammonite (Lobolytoceras costellatum) was scanned in 2007 at the Fachbereich Veterinärmedizin (Klinik und Poliklinik für kleine Haustiere), Freie Universität Berlin-Düppel using a medical CT scanner from $\mathrm{GE}^{\circledR}$ with a resolution of $1 \mathrm{~mm}$ (Fig. 3). The objects of interest can easily be adjusted within the FOV by positioning them on a movable scanner table, which can be lifted up/down and moved back/forth. Further calibrations are not necessary because the x-ray source will rotate around the object(s). In comparison to surface scanning the reflectivity of the surface or organic matter is not problematic for x-ray scans (same for micro-CT, nano-CT, 
Table 1. Devices used in this study to acquire data, with range of resolution, remarks and investigated examples.

\begin{tabular}{|c|c|c|c|c|c|c|c|}
\hline Method & Device & Facility & Resolution & $\begin{array}{l}\text { Applicable object } \\
\text { dimensions, } \\
\text { restrictions, } \\
\text { remarks }\end{array}$ & Example & $\begin{array}{l}\text { Raw data } \\
\text { volume }\end{array}$ & $\begin{array}{l}\text { Acquisition } \\
\text { time }\end{array}$ \\
\hline $\begin{array}{l}\text { Surface } \\
\text { scanner }\end{array}$ & $\begin{array}{l}\text { BREUCKMANN } \\
\text { optoTOP-HE (OT1301- } \\
\text { HE6-L100-060 sensor) } \\
\text { BREUCKMANN } \\
\text { optoTOP-HE (OT1289- } \\
\text { HE6-L100-225 sensor) }\end{array}$ & $\begin{array}{l}\text { Steinmann-Institut, } \\
\text { Universität Bonn, } \\
\text { Germany }\end{array}$ & $\begin{array}{l}16 \mu \mathrm{m}(\mathrm{FOV} \\
60 \mathrm{~mm}) \\
60 \mu \mathrm{m}(\mathrm{FOV} \\
225 \mathrm{~mm})\end{array}$ & $\begin{array}{l}\text { Unlimited object } \\
\text { size, constant } \\
\text { resolution; mat- } \\
\text { finished surface } \\
\text { is needed, deep } \\
\text { narrow holes } \\
\text { are difficult }\end{array}$ & $\begin{array}{l}\text { Spirula spirula } \\
\text { (Fig. 2b and e) } \\
\\
\text { Spirula spirula } \\
\text { (Fig. 2a and d) }\end{array}$ & $0.5 \mathrm{~GB}$ & $0.5 \mathrm{~h}$ \\
\hline $\begin{array}{l}\text { Medical } \\
\text { CT }\end{array}$ & $\begin{array}{l}\text { SIEMENS Somatom } \\
\text { Definition Dual } \\
\text { Source CT }\end{array}$ & $\begin{array}{l}\text { Klinik und Poliklinik } \\
\text { für kleine Haustiere, } \\
\text { FU Berlin-Düppel, } \\
\text { Germany } \\
\text { Knappschafts- } \\
\text { krankenhaus } \\
\text { Bochum, Germany }\end{array}$ & $\begin{array}{l}\text { Up to } \\
1 \mathrm{~mm} \\
\text { Up to } \\
500 \mu \mathrm{m}\end{array}$ & $\begin{array}{l}1 \times 1 \times 1.7 \mathrm{~m}, \\
<200 \mathrm{~kg} ; \text { special } \\
\text { room with x-ray } \\
\text { absorption }\end{array}$ & $\begin{array}{l}\text { Lobolytoceras } \\
\text { costellatum } \\
\text { (Fig. 3a and b) }\end{array}$ & $255 \mathrm{MB}$ & $\begin{array}{l}\text { A few } \\
\text { minutes }\end{array}$ \\
\hline $\begin{array}{l}\text { Micro- } \\
\text { CT }\end{array}$ & $\begin{array}{l}\text { GE Phoenix|x-ray } \\
\text { v|tome|x s ( } 240 \mathrm{kV} \\
\text { microfocus tube) } \\
\text { GE Phoenix|x-ray } \\
\text { v|tome|x s ( } 180 \mathrm{kV} \\
\text { nanofocus tube) }\end{array}$ & $\begin{array}{l}\text { Steinmann-Institut, } \\
\text { Universität Bonn, } \\
\text { Germany }\end{array}$ & $\begin{array}{l}6-246 \mu \mathrm{m} \\
(\text { detector size } \\
40 \times 40 \mathrm{~cm}) \\
\text { Up to } 2 \mu \mathrm{m} \\
(\text { detector size } \\
40 \times 40 \mathrm{~cm})\end{array}$ & $\begin{array}{l}30 \times 18 \times 18 \mathrm{~cm} \text {, } \\
<5 \mathrm{~kg} ; \text { size } \\
\text { influences } \\
\text { resolution }\end{array}$ & $\begin{array}{l}\text { ?Cadoceras sp. (Fig. 10a } \\
\text { and d), Nautilus pompilius } \\
\text { (Figs. } 4,5,6,7 \text { ), Spirula } \\
\text { spirula (Fig. 2c and f) } \\
\text { Gaudryceras sp. (Fig. 1b), } \\
\text { Eleganticeras } \text { sp. (Fig. 1a) }\end{array}$ & $\begin{array}{l}\text { Up to } \\
4 \mathrm{~GB} \\
\text { Up to } \\
8 \mathrm{~GB}\end{array}$ & $1-2 \mathrm{~h}$ \\
\hline $\begin{array}{l}\text { Nano- } \\
\text { CT }\end{array}$ & $\begin{array}{l}\text { GE Phoenix } \mid \mathrm{x}-\mathrm{ray} \\
\text { nanotom }(180 \mathrm{kV} \\
\text { nanofocus tube })\end{array}$ & $\begin{array}{l}\text { GFZ Potsdam, } \\
\text { Germany }\end{array}$ & $\begin{array}{l}\text { Up to } \\
500 \mathrm{~nm}\end{array}$ & $\begin{array}{l}15 \times 12 \times 12 \mathrm{~cm} \text {, } \\
<2 \mathrm{~kg} ; \text { size } \\
\text { influences } \\
\text { resolution }\end{array}$ & $\begin{array}{l}\text { ?Cadoceras sp. (Fig. 10b } \\
\text { and e), Spirula spirula } \\
\text { (Figs. } 8,9 \mathrm{a} \text { and b) }\end{array}$ & $\begin{array}{l}\text { Up to } \\
16 \mathrm{~GB}\end{array}$ & $2-5 \mathrm{~h}$ \\
\hline $\mathrm{SR} \mu \mathrm{CT}$ & $\begin{array}{l}\text { Advanced Photon } \\
\text { Source (APS) }\end{array}$ & $\begin{array}{l}\text { Argonne, Illinois, } \\
\text { USA }\end{array}$ & $\begin{array}{l}\text { Up to } \\
0.7 \mu \mathrm{m}\end{array}$ & $\begin{array}{l}5 \times 5 \times 5 \mathrm{~mm}, \\
\text { size influences } \\
\text { resolution }\end{array}$ & $\begin{array}{l}\text { ?Cadoceras sp. (Fig. 10c } \\
\text { and f), Spirula spirula } \\
\text { (Fig. } 9 \mathrm{c})\end{array}$ & $\begin{array}{l}\text { Up to } \\
33 \mathrm{~GB}\end{array}$ & $20 \mathrm{~min}$ \\
\hline MRI & $\begin{array}{l}\text { BRUKER Avance } \\
\text { NMR spectrometer }\end{array}$ & $\begin{array}{l}\text { Saarbrücken, } \\
\text { Germany }\end{array}$ & $100 \mu \mathrm{m}$ & $10 \times 10 \times 30 \mathrm{~mm}$ & $\begin{array}{l}\text { Hibolithes jaculoides } \\
\text { (Fig. 11) }\end{array}$ & & $\begin{array}{l}\text { Up to } \\
\text { days }\end{array}$ \\
\hline
\end{tabular}

and $\mathrm{SR} \mu \mathrm{CT}$ ). Scan parameters are fixed in the associated scan programs. Due to the open construction of the relatively large medical CT scanners a special room with x-ray absorption properties and low vibrations is necessary. Contrary to the high costs of acquisition of a medical CT scanner, they are widely distributed in different kinds of hospitals and therefore relatively easy to get access to. Scan times range between a few seconds and a few minutes depending on the size of the object of interest. The reconstruction process (post-processing) can be completed in a few minutes due to the small amount of data that can be operated on a standard desktop PC. Open source software (e.g., ImageJ) is suitable for the post-processing work. Due to the low resolution the smallest objects should generally not be smaller than $1 \mathrm{~cm}$. The upper limit of object size is around $180 \mathrm{~cm}$ in diameter, which is six times larger compared to a micro-CT, but can be much longer. Dual-energy scans are possible with medical CT-scanner devices using two x-ray sources and two detectors at the same time; the scanning speed is increased and of exceptional quality. Several kinds of scan artifacts may occur in the reconstructed image due to limited x-ray flux or use of polychromatic radiation, finite resolution, discrete sampling and $\mathrm{x}$-ray scatter, hindering a successful reconstruction of shapes (Davis and Elliott, 2006). The polychromatic xray beam is problematic in producing beam-hardening scan artifacts (among others). Different absorption properties of the scanned materials (e.g., shell, air and/or matrix) lead to stronger absorption of the low-energy x-rays than the highenergy x-rays (Stock, 2006; Tafforeau et al., 2006). Thus, the hard parts of the $\mathrm{x}$-ray spectrum become dominant, leading to a confusing increase in the linear absorption coefficient, resulting in bright non-informative areas on the scans (ring artifacts, etc.).

\subsection{Micro-computed tomography (micro-CT)}

The advantage of micro-CT technology, developed at the end of the 1980s, over conventional CTs is a significantly higher achievable resolution. Scanners are available from different companies (e.g., GE ${ }^{\circledR}$, Skyscan $^{\circledR}$, FRAUNHOFER ${ }^{\circledR}$ ) and are 
increasingly accessible in different scientific facilities with various fields of interests. A great number of micro-CT machines are chambered devices that do not need a special radiation protection area or an extra room with special lead coating for security, as a protective lead coating is included in the chambered set-up. The desktop micro-CTs of Skyscan (now BRUKER ${ }^{\circledR}$ micro-CT) and CT-MINI FRAUNHOFER ${ }^{\circledR}$ are examples of relatively small and mobile devices. The maximum size of the objects to be scanned depends on the detector size and the scanning chamber of the device. Objects larger than the detector may be scanned in parts and merged virtually afterwards. The used device has two different tubes (Table 1). There are also micro-CTs available on the market independent of a chamber set-up (for example the L products of $\mathrm{GE}^{\circledR}$ ); here special rooms and technicians are necessary. Within a chambered device objects are mounted on a movable and rotatable computerized numerical control table (CNC table), and depending on the distance to the $\mathrm{x}$ ray source the resolution of the scan changes. As a rule, the closer you get, the higher the resolution you can achieve. An advantage is that several small objects can be scanned at the same time with the same resolution. The utilization of highresolution scans allows the visualization of minute outer and inner structures (e.g., ornamentation and septa of smaller dimensions and with increased precision compared to medical CT scans) and the creation of detailed 3-D models of the scanned objects. For objects within or filled with a matrix a successful segmentation depends on the state of preservation. A considerable difference in absorption properties between the structure of interest (fossil) and the surrounding matrix is therefore necessary. The scan process is fully automatic, except for the adjustments before the start. Extensive maintenance (filaments, detector, etc.) is necessary. Only a few software systems for 3-D image segmentation do exist (e.g., ZIB-Amira or provided by the micro-CT manufacturers) that can handle large data sets and provide algorithms for the geometric reconstruction of multi-component structures. Normally alignment optimization, beam-hardening and ringartifact corrections are included in the reconstruction algorithm. As many devices produce different raw data formats the reconstruction after scanning elsewhere is problematic. Due to the well-known sampling theorem (Nyquist, Shannon, Kotelnikov, Whittaker; see Marks II, 1991) the spatial resolution of the scanning system needs to be at least twice as high as the smallest structure that needs to be reconstructed from the image data. For example, if the highest resolution of a micro-CT is $2-5 \mu \mathrm{m}$, the structure of interest needs to be at least $4-10 \mu \mathrm{m}$. The maximum resolution mode itself produces a very low signal to noise ratio (SNR) due to high sensitivity and sensor artifacts. That noise degrades the image quality and hinders automatic segmentation algorithms to distinguish between the structures of interest and non-relevant structures and noise. For a comprehensive study comparing different micro-CT devices from different manufacturers see Drews et al. (2008).

\subsection{Nanofocus-computed tomography (nano-CT)}

In $2006 \mathrm{GE}^{\circledR}$ developed the phoenix nanotom ${ }^{\circledR}$ (nano-CT; Table 1), a new tomograph device with improved resolution and contrast properties (Drews et al., 2008). With its improved detector using CCD or CMOS technology, the nanotom ${ }^{\circledR}$ series was designed for material sciences but can also be used for geological and biological samples. Like the micro-CT the nanotom ${ }^{\circledR}$ is a chambered device that includes lead coating and has a CNC table. Compared to a micro-CT from the same company, scan artifacts are reduced and the contrast of the resulting grey-scale images is increased, while the time effort stays the same. In addition, data acquisition needs half the time for the same image quality. Resolution was improved with the highest value at $0.5 \mu \mathrm{m}$, but the detail detectability lies at about 200-300 nm (Brunke et al., 2008). Thus, the dimension of the structure of interest suitable for a successful reconstruction is reduced to about $1-2 \mu \mathrm{m}$. In addition, the reconstruction of the scanned data is faster using a time-optimized algorithm. The time necessary to scan a certain object depends on object size, scan resolution, number of images taken, rotational angle and time interval of rotation, and may vary between several minutes and several hours. High acquisition costs and the extensive maintenance (filaments, detector, etc.) are the reasons why the nanotom ${ }^{\circledR}$ is not widely distributed yet, thus hampering easy access. However, with respect to spatial resolution nano-CT can compete with many absorption contrast set-ups at synchrotron radiation facilities (Withers, 2007).

\subsection{Synchrotron radiation based micro-computed tomography $(\mathrm{SR} \mu \mathrm{CT})$}

SR $\mu C T$ was introduced in the 1980s (see Bonse and Busch, 1996) and differs from common micro-CT in using monochromatic x-ray beams (Table 1). While reconstructed data of a polychromatic x-ray scan seem blurred when compared to a monochromatic x-ray scan, the data produced during a synchrotron scan result in accurate absorption information on the different materials because the strong bundled $\mathrm{x}$-rays hit the object with a very high intensity (Tafforeau et al., 2006). Consequently the images of a synchrotron scan are at high contrast and high resolution. The $\mathrm{x}$-rays used for $\mathrm{SR} \mu \mathrm{CT}$ are a side product of the acceleration of the electrons induced in the storage ring of the synchrotron facility, which are deflected at several stations called beamlines (www.esrf.eu). Since the electrons are only induced in scheduled time frames the user depends on the main beam working stably. A huge setup (e.g., Advanced Photon Source (APS) Argonne (Illinois), storage ring circumference 1104 m; European Synchrotron Radiation Facility (ESRF) Grenoble (France), storage ring circumference $844 \mathrm{~m}$ ) with several technicians is necessary to induce the electrons. At least one additional technician is necessary on each beamline the user is working on. The scan time for one small object 
(5 mm) takes about 5-20 min, depending on the set-up, but larger objects can also be scanned with high accuracy and resolution. High resolution means in this case that the resolution can be less than $0.7 \mu \mathrm{m}$ (Baruchel et al., 2006; Friis et al., 2007; Perrichot et al., 2008; Pouech et al., 2010; Sanchez et al., 2012; Tafforeau and Smith, 2013; Moreau et al., 2014; Fig. 10). The great disadvantage of synchrotron technology is the huge amount of data that are produced during a single scan. The larger an object is, the larger the data set gets (easily several terabytes), meaning that short- and long-term data storage can be a potential problem. The data size lengthens the reconstruction time afterwards to several days, depending on the number of specimens scanned. Since only a few synchrotron facilities have been available worldwide so far, this method is rather hard to get access to, depending mainly on a scan proposal with an accurate project summary. A successful proposal is typically granted beam time for several days. Besides SR $\mu \mathrm{CT}$, other methods are usually available at these facilities (e.g., phase contrast tomography or holotomography). For details the reader is referred to Stock (2006) and Tafforeau et al. (2006).

\subsection{Magnetic Resonance Imaging (MRI)}

Like CT scanning, MRI has its origin in medical sciences and clinical practice. Comparable to computed tomography it allows the study of skeletal hard parts and physiological processes in vivo. In contrast to CT scanning, MRI allows the differentiation between various types of soft tissue (organs). For fossil cephalopods this method becomes interesting if a contrast agent like hydrogen was trapped within the skeletal material or an existing gap between the internal mold and the surrounding rock can be filled with a contrast agent. This gap usually represents the original place and morphology of the now dissolved shell. Under fortunate conditions (low porosity, no connected pore space) the gap filled with the agent allows the reconstruction of the shell. There are a few companies distributing MRI scanners (e.g., SIEMENS ${ }^{\circledR}$, PHILIPS $^{\circledR}$, GE $^{\circledR}$, and BRUKER ${ }^{\circledR}$; Table 1). Due to relaxation constants and proton concentration, the resolution of the MRI images is limited to $40 \mu \mathrm{m}$ but also depends on object size, e.g., for objects of $3 \times 3 \times 3 \mathrm{~cm}$ it lies at 60 $80 \mu \mathrm{m}$ (A. Ziegler, personal communication, 1991). Therefore, the reconstruction of structures of interest with dimensions smaller than $40 \mu \mathrm{m}$ is not possible with this method. Sample size depends on the dimensions of the spectrometer used and the possibility to use the method itself depends on the presence of a detectable contrast agent (e.g., water). Because the x-ray source will rotate around the objects, a special fixture of the object is not needed, but it should be positioned in a stable manner to avoid movements of the object during the scan. Post-processing and visualization of the images can be done using different software packages (e.g., ImageJ or Amira). The resulting file size depends on the size of the object and the resolution. If no contrast agents are avail- able this method cannot be applied. Another issue is the timeconsuming process, up to one week, to obtain the data, which depends again on the proton concentration, the power of the used magnet and SNR. Some artifacts may occur, like single pixels with high signal intensity. The loss of signal intensity towards the edges of FOV is caused by the coil geometry used to send and receive the frequency signals. For further details the reader is referred to Mietchen et al. $(2005,2008)$ for fossils and to Ziegler et al. (2011) for living forms.

\section{Application in cephalopod studies}

\subsection{Surface scanning}

For comparison two surface scans of different resolutions ( $60 \mu \mathrm{m}$ : Fig. $2 \mathrm{a}$ and d; and $16 \mu \mathrm{m}$ : Fig. $2 \mathrm{~b}$ and e) and a microCT scan $(60 \mu \mathrm{m}$ : Fig. $2 \mathrm{c}$ and $\mathrm{f})$ of the shell of the extant cephalopod $S$. spirula were used. The greatest diameter of the loosely coiled Spirula shell used here is $1.6 \mathrm{~cm}$. For loosely coiled heteromorph ammonoids (Spirula is comparable) all standard measurements (see Korn, 2010) are achievable with this method (whorl width, whorl height $=$ apertural height, diameter, umbilical width, whorl interspace and ornamentation pattern). For planispiral fossil shells partly preserved in surrounding rock material it is not possible to obtain the whorl width and apertural height. Due to overlapping whorls whorl height is not the same as apertural height in this case. The time necessary to acquire the data and the amount of raw data of the surface scans are comparable in both sensors (Fig. 2a and b, Table 2). Normally more scans have to be done with the sensor with the smaller FOV to capture the same area, but with a small specimen it is negligible (17 single scans in Fig. 2a, and 14 in Fig. 2b). Issues of this technique are deep pits and narrow openings because of the fixed sensor set up, in this case the inner whorls and the whorl interspace (Fig. 2a and b). One obvious difference between the scans of two different resolutions is the ornamentation of the shell. The constrictions of the shell are more precise in the $16 \mu \mathrm{m}$ resolution surface scan (Fig. 2b). Therefore the polygonal model file (.stl) is much larger, with a resolution of $16 \mu \mathrm{m}$ (6 MB versus $600 \mathrm{~KB}$ with $60 \mu \mathrm{m}$ resolution). After the acquisition of a raw polygonal model a post-processing step is necessary, for instance using PolyWorks ${ }^{\circledR}$ to close holes (the blue area in Fig. 2a and b). This procedure uses the margins of the holes to extrapolate the closed surface. The time necessary for post-processing depends on the desired accuracy (approx. 15 min in Fig. 2d and e). The comparable results produced with the micro-CT $(60 \mu \mathrm{m}$ resolution) are given in Fig. 2c (slice of the image stack) and Fig. 2f (post-processed polygonal model). After 30 min up to more than one hour (depending on the scan settings) an image stack can be produced. This will be post-processed by segmentation or isosurface rendering. In our example the best result for the rather small Spirula shell was obtained from the $60 \mu \mathrm{m}$ micro-CT 

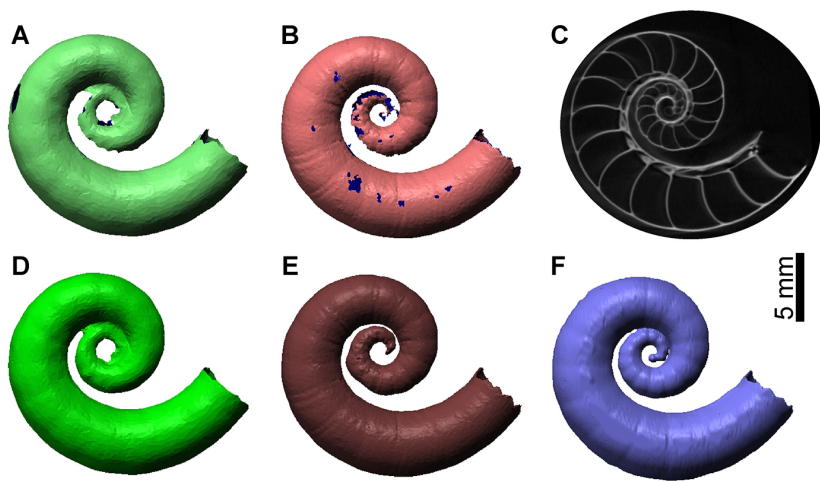

Figure 2. Raw scans (A-C) and post-processed polygonal models (D-F) of Spirula spirula (1.6 cm in diameter). (A, D) surface scan with $60 \mu \mathrm{m}$ resolution; (B, E) surface scan with $16 \mu \mathrm{m}$ resolution; (C, F) micro-CT scan with $60 \mu \mathrm{m}$ resolution; while (C) is a single slice of the micro CT-scan image stack.

scan (Fig. 2f). The constrictions and the protoconch, the first chamber in the center of the shell, are visible in the microCT data, which is not the case for both surface scans. The polygonal model file size (7.6 MB) is comparable with the $16 \mu \mathrm{m}$ resolution surface scan, but the size of the raw data is seven times greater. Due to the open and light construction of surface scanners it would be possible to create a polygonal model of the largest ammonite Parapuzosia seppenradensis known so far with both sensors ( $16 \mu \mathrm{m}$ and $60 \mu \mathrm{m})$.

In addition, high-resolution surface scanning of objects with a simple geometry (e.g., cubes) contributes to volume calculations in order to achieve an exact buoyancy calculation for chambered cephalopods. We first applied this approach to shells of the extant Nautilus and Spirula, and then transferred it to the cephalopod group of extinct ammonoids. Therefore we scanned a massive calcite crystal with both sensors $(16 \mu \mathrm{m}$ and $60 \mu \mathrm{m})$ of the surface scanner and calculated its volume. With knowledge of its volume (Table 2) obtained from the surface scan the calcite crystal was subsequently scanned together with the cephalopod shells in a micro-CT (see the application of micro-CT and the discussion). Here the crystal now acts as a reference body according to the quantitative computed tomography (QCT) approach. QCT is a medical technique developed in the 1970s to measure bone density. During this approach a standard material with similar absorption properties (called a phantom) to the material being scanned is used. The object of interest and the phantom are scanned together; in the case of bone the phantom is generally composed of hydroxyapatite (Adams, 2009).
Table 2. Calculated densities of a calcite crystal (29.2 g) using the polygonal models made from surface and micro-CT scans at different resolutions. The volumes of the polygonal models were measured using PolyWorks/IMEdit.

\begin{tabular}{lcc}
\hline $\begin{array}{l}\text { Scan } \\
\text { (resolution) }\end{array}$ & $\begin{array}{c}\text { Volume } \\
\left(\mathrm{mm}^{3}\right)\end{array}$ & $\begin{array}{c}\text { Density } \\
\left(\mathrm{g} \mathrm{cm}^{-3}\right)\end{array}$ \\
\hline Surface scan $(60 \mu \mathrm{m})$ & 10958.7 & 2.665 \\
Surface scan $(16 \mu \mathrm{m})$ & 10900.5 & 2.679 \\
Micro-CT scan $(60 \mu \mathrm{m})$ & 10925.6 & 2.673 \\
\hline
\end{tabular}

\subsection{Computed tomography (CT)}

In order to scan objects that exceeded the maximum spatial dimensions for micro- or nano-CTs a medical CT scanner was used. In addition to the scanning of large specimens, a second application of medical CT scanners is to perform prescans to test rock samples for the content of suitable material (e.g., rare hollow ammonites) and contemporaneous localization of these fossils within a larger rock sample. Due to their short scan time medical CT scanners can be used to scan a large amount of material in a short time interval (Fig. 3c). We scanned a completely chambered specimen of the Upper Jurassic lytoceratid ammonite Lobolytoceras costellatum from Madagascar with a shell diameter of $61.5 \mathrm{~cm}$ and most of its aragonitic shell preserved (Fig. 3a and b). The final part of the conch was filled with calcareous sediment with similar absorption properties compared to the shell, which leads to a low SNR hindering a visualization of internal septa (Fig. 3a, white arrow). The inner part of the same specimen was filled with material of different absorption properties compared to the preserved shell, allowing the recognition of the complexly folded septa (Fig. 3a, black arrow). Besides the major elements of the septa, the septal lobe - a character that constitutes the monophyly of the Lytoceratoidea (Hoffmann, 2010) - is visible in the median plane parallel to the coiling axis (Fig. 3a, red arrows). Growing in an apical direction the internal lobe comes into contact with the preceding septum and is attached on its surface, generating the structure called a septal lobe. The volume rendering scalar values of the 3-D image is integrated in the direction of the projection, producing a transparent image that shows the sedimentary infill of nearly all of the earlier chambers with calcareous mud but which also shows slight differences between shell and infill, imitating a suture line (Fig. 3b). The recognition of internal major structures invisible to the naked eye may be useful for planned subsequent technical preparation of a certain structure (e.g., the surface of the ammonoid septum as described for Lobolytoceras costellatum by Schreiber and Hoffmann, 2009).

Besides this a first check for the state of preservation can be performed, allowing for a decision on further treatment. If the fossil material seems to be suitable the data from the 


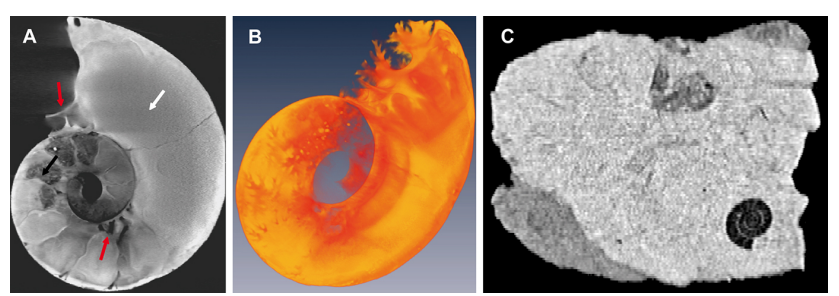

Figure 3. Medical CT scans of Lobolytoceras costellatum (A, B; scan resolution $=1 \mathrm{~mm}$ ) from the Oxfordian (Upper Jurassic) of Madagascar (about $61.5 \mathrm{~cm}$ in diameter) and Craspedites sp. from the Volgian Kostroma region (Russia) (C, res. $0.5 \mathrm{~mm}$ ). (A) The specimen lacks the body chamber. The septal lobe (red arrows) is a diagnostic feature of all Lytoceratoidea. Due to similar density and absorption properties the sediment has a similar grey value compared to the aragonitic shell. Distinguishing between both materials is problematic (white arrow). Different absorption properties of the aragonitic shell and the secondary infill led to better SNR, which allows the recognition of internal structures (black arrow). (B) scalar values of the 3-D image are integrated into the volume rendering in the direction of the projection, producing a transparent image that shows the sedimentary infill. Note the sculptured surface of the last preserved septum. (C) orthosclice of a sediment block $(9 \times 7 \times 6 \mathrm{~cm})$ pre-scanned in search for hollow material; note that one hollow specimen of Craspedites sp. is in the lower right corner.

pre-scan can subsequently be used to extract the fossils from the rock by using computer numerical controlled (CNC) devices (saws, mills, water jet cutters). After extracting the fossil from the surrounding rock a high-resolution scan is necessary to create a three-dimensional model including all internal and external features of the ammonite. Due to the low resolution of the medical CT, surface details and the thin internal septa of the scanned ammonite are not or hardly visible. Therefore these pre-scans are not suitable for a detailed reconstruction.

\subsection{Micro-computed tomography (micro-CT)}

We scanned N. pompilius, S. spirula and a juvenile ammonite (?Cadoceras sp.), used as representatives of large, medium and small objects, with the Phoenix|x-ray v|tome|x s 240 micro-CT device. The results from micro-CT and nano-CT scans for the juvenile ?Cadoceras will be compared within the synchrotron chapter, and for Spirula see the nano-CT chapter. In this paragraph we focus on one shell of $N$. pompilius, with a diameter of $17 \mathrm{~cm}$, scanned with different resolutions using CT and micro-CT. The obtained data sets were subsequently visualized and segmented, and scan artifacts were removed with the Avizo Fire 7.0 (Avizo VSG, Düsseldorf, Germany) software package.

The application of micro-CT data in cephalopod research is exemplified in the calculation of the buoyancy of the Nautilus. The term buoyancy (B) in this case refers to the total effective weight of the animal while submerged in a still column of water (neglecting dynamic forces such as swimming, current motion and testing the ability of the shell to offset the weight of the animal under water). The buoyancy is defined as the difference between the weight of the animal $\left(F_{\mathrm{G}}\right)$, meaning the animal's weight measured in air, and the buoyant force $\left(F_{\mathrm{B}}\right)$, which is the weight of the displaced water equal to the total volume of the animal (Archimedes principle). This calculation requires accurate values of the volume of the shell, each chamber volume of the shell, and the volume of the soft body. These volumes can be drawn directly from the CT data and used to calculate the mass, weight, and buoyant force. Density values for both the shell, which range from $2.5 \mathrm{~g} \mathrm{~cm}^{-3}$ to $2.7 \mathrm{~g} \mathrm{~cm}^{-3}$, and the soft body, which range from $1.05 \mathrm{~g} \mathrm{~cm}^{-3}$ to $1.07 \mathrm{~g} \mathrm{~cm}^{-3}$, were taken from values reported in the literature summarized in Hoffmann and Zachow (2011). The minimum and maximum density values as well as the volume data estimated from the CT scans were used to calculate a range of potential weights for the animal, which are then applied for the buoyancy calculation (Fig. 4), i.e., $\mathrm{B}=F_{\mathrm{B}}-F_{\mathrm{G}}$.

In preparation for a final buoyancy calculation a validation test was performed on three data sets of the same Nautilus shell in order to ensure that accurate volume data can be extracted from the CT data. The first scan was at a resolution of $172 \mu \mathrm{m}$, the second at $190 \mu \mathrm{m}$ and a third scan with a medical CT scanner at a resolution of $500 \mu \mathrm{m}$. The first two data sets were segmented using the same minimum-maximum greyscale threshold values (26764-64749). The threshold was chosen individually. The estimations drawn from the higher resolution scan resulted in a shell mass closer to the true shell mass of $203.5 \mathrm{~g}$ (Table 3).

However, the calculated shell mass is inaccurate compared to the actual measured mass (up to a $23 \%$ difference), which was largely caused by the individual manipulation of the threshold but, as will be shown later, also by other sources of error. We therefore tested the QCT approach with different reference bodies $\left(\mathrm{Al}_{2} \mathrm{O}_{3}\right.$ and $\mathrm{SiO}_{2}$ high precision spheres with a deviation of less than $10 \mu \mathrm{m}$ and a calcite crystal). We scanned the three reference bodies together with the Nautilus shell at a resolution of $175 \mu \mathrm{m}$ (Fig. 5a). For all three reference bodies we determined the threshold for the segmentation tool separately till the selected volume meets the calculated volume of the precision spheres and the calcite crystal. The volume for the calcite crystal was obtained from highresolution $(16 \mu \mathrm{m})$ surface scans as mentioned above. The three different threshold values were subsequently applied to segment the shell material. This same QCT process was repeated with the medical CT data; however, complications arose during the segmentation process. Only one of the reference bodies, the calcite crystal, was useful for segmenting the shell, as the thresholds taken from both of the spheres were not accurate enough for selecting most of the shell material. A correction for an accurate threshold would have required manual tracing of most of the shell and therefore would have resulted in invalidating the purpose of the QCT procedure. It should be noted that even the calcite crystal threshold 


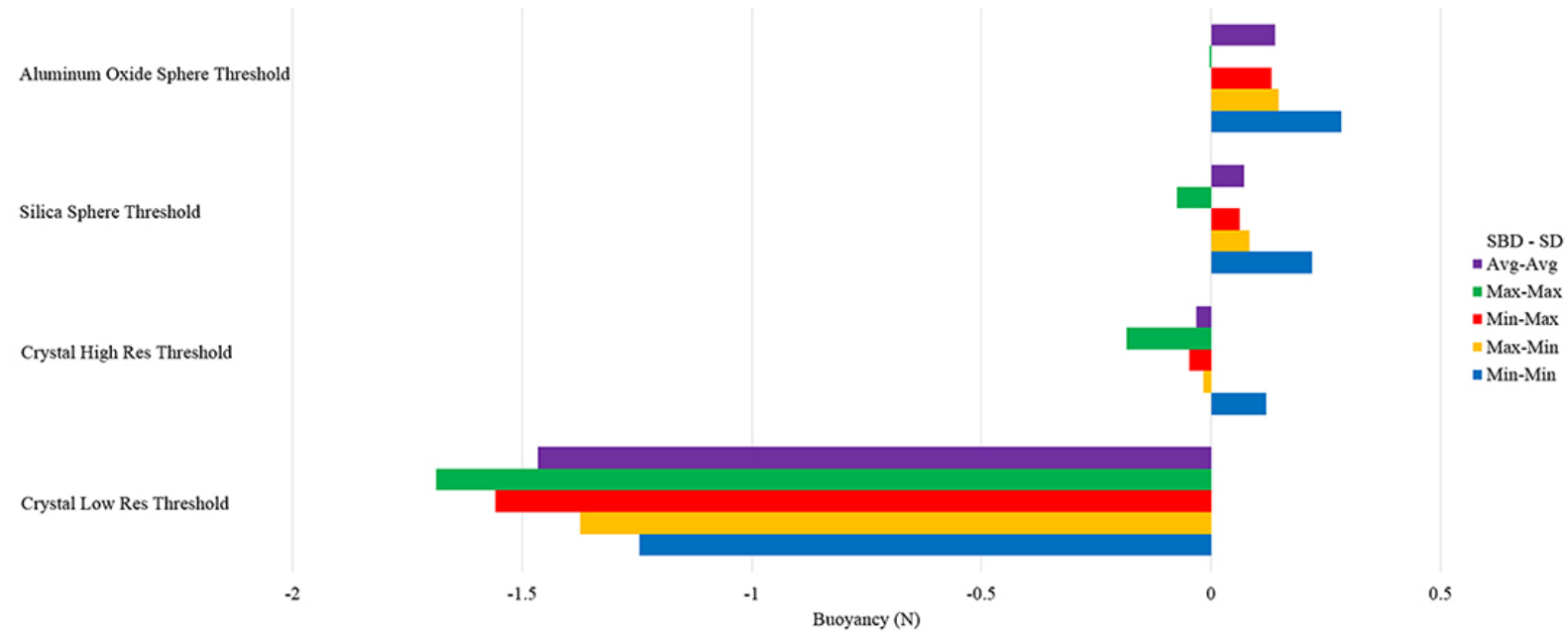

Figure 4. Buoyancy calculation based on a micro-CT scan (res. $175 \mu \mathrm{m}$, high resolution) of a Nautilus pompilius shell (17 cm in diameter) together with three reference bodies (phantoms). The reference bodies were two high-precision spheres $\left(\mathrm{Al}_{2} \mathrm{O}_{3}, \mathrm{SiO}_{2}\right)$ and one calcite crystal, all with exact known dimensions and volumes. For each reference body we present five buoyancy values for minimum, maximum and average density values for soft body (SBD), $1.05 \mathrm{~g} \mathrm{~cm}^{-3}$ and $1.07 \mathrm{~g} \mathrm{~cm}^{-3}$, and shell (SD), $2.5 \mathrm{~g} \mathrm{~cm}^{-3}$ and $2.7 \mathrm{~g} \mathrm{~cm}^{-3}$ (Hoffmann and Zachow, 2011 ). The best approximation is the average-average value. Contrary to the small volume of the shell, the different density values have a higher impact on the buoyancy calculation compared to the soft body density, which is close to sea water. To demonstrate the effect of low scan resolution (here $500 \mu \mathrm{m}$ ) on the buoyancy calculation we present one set of calculations (Crystal Low Res threshold) for the same calcite crystal (see text for further explanations) used for the $175 \mu \mathrm{m}$ scan. Buoyancy calculation shows a marked negative shift compared with the values drawn from the high-resolution scan. Buoyancy calculation was operated under the assumption that all phragmocone chambers were gas filled and dry while the body chamber was completely filled with soft tissue.

Table 3. Influence of the scan resolution on volume/mass calculations of the Nautilus shell (actual mass $203.5 \mathrm{~g}$ ), with minor corrections for artifacts. Only shell material that was selected with the obtained threshold is considered here; no attempt is made manually to segment unselected shell material (thin septa).

\begin{tabular}{lccc}
\hline $\begin{array}{l}\text { Resolution } \\
(\mu \mathrm{m})\end{array}$ & $\begin{array}{c}\text { Volume } \\
\left(\mathrm{mm}^{3}\right)\end{array}$ & $\begin{array}{c}\text { Shell mass } \\
(\mathrm{g}) \text { with } \\
2.5 \mathrm{~g} \mathrm{~cm}^{-3} \\
2.7 \mathrm{~g} \mathrm{~cm}^{-3}\end{array}$ & $\begin{array}{c}\text { Difference } \\
\text { from the } \\
\text { actual mass } \\
(\%)\end{array}$ \\
\hline 190 & & 236.70 & +15.08 \\
& 94679.95 & 255.63 & +22.71 \\
172 & 90179.10 & 225.45 & +10.23 \\
& & 243.48 & +17.89 \\
\hline
\end{tabular}

required manual correction, although this was largely limited to the first whorl. The small volume of the first whorl would influence only little the total mass estimation and is likely partially responsible for at least some of the discrepancy between the calculated and measured mass of the shell (the same is true in the higher resolution scans which is discussed later in this section). The data from the medical CT showed a tremendous difference between the calculated mass and the measured mass. Using the calcite crystal as a reference, the shell was calculated to weigh minimally $399.3 \mathrm{~g}$ and maximally $431.2 \mathrm{~g}$ at $2.5 \mathrm{~g} \mathrm{~cm}^{-3}$ and $2.7 \mathrm{~g} \mathrm{~cm}^{-3}$ respectively. This means a percentage difference of +65 and $+71.75 \%$. Applying the calcite crystal threshold to the micro-CT data at $175 \mu \mathrm{m}$ (compared to the $500 \mu \mathrm{m}$ medical resolution) the resulting percentage difference was $+4.9 \%$ (at $2.5 \mathrm{~g} \mathrm{~cm}^{-3}$ ) and $+12.6 \%\left(2.7 \mathrm{~g} \mathrm{~cm}^{-3}\right)$.

The smallest deviation between the actual mass and the calculated mass of the Nautilus shell was calculated using the $\mathrm{SiO}_{2}$ sphere and, surprisingly, the largest deviation was calculated using the calcite crystal. Compared to the values achieved without using a reference body, all presented values calculated with the reference bodies are much closer to the actual shell mass (Table 4a). This also holds true after the remaining shell parts (earliest very thin septa) were manually segmented and added to the shell mass (Table $4 b$ ). Due to the small volume of the thin shell elements (less than $0.5 \mathrm{~cm}^{2}$ ) the mass increase remained small. The buoyancy of the three fully segmented shells, each made with the application of one of the three reference bodies, was calculated (Fig. 4).

The large deviation between actual and calculated mass achieved for the calcite crystal may result from the differences in the thickness of both objects (calcite crystal, shell). The differences in the grey-scale values seen in the primary image data depend on absorption properties which are related to chemical composition and thickness of the material. Solid material with a high density has lighter grey-scale values based on the linear x-ray absorption coefficients compared to thinner material of the same composition, while air 
Table 4. Influence of different reference bodies at the same resolution $(175 \mu \mathrm{m})$ as volume/mass calculations of the Nautilus shell (203.5 g) with: (a) minor corrections for artifacts (only shell material that was selected with the obtained threshold is considered here; no attempt manually to segment unselected shell material (thin septa)); and (b) fully segmented and corrected models.

\begin{tabular}{|c|c|c|c|c|c|c|c|c|}
\hline \multirow[b]{2}{*}{$\begin{array}{l}\text { Reference } \\
\text { body }\end{array}$} & \multirow[b]{2}{*}{$\begin{array}{l}\text { Volume } \\
{\left[\mathrm{mm}^{3}\right]}\end{array}$} & \multirow[b]{2}{*}{$\begin{array}{l}\text { Density } \\
\left(\mathrm{g} \mathrm{cm}^{-3}\right)\end{array}$} & \multicolumn{3}{|c|}{ (a) Nautilus shell } & \multicolumn{3}{|c|}{ (b) Nautilus shell } \\
\hline & & & $\begin{array}{l}\text { Volume } \\
\left(\mathrm{cm}^{3}\right)\end{array}$ & $\begin{array}{l}\text { Mass (g) with } \\
2.5 \mathrm{~g} \mathrm{~cm}^{-3} \\
2.7 \mathrm{~g} \mathrm{~cm}^{-1}\end{array}$ & $\begin{array}{l}\text { Difference } \\
\text { from actual } \\
\text { mass }(\%)\end{array}$ & $\begin{array}{l}\text { Volume } \\
\left(\mathrm{cm}^{3}\right)\end{array}$ & $\begin{array}{l}\text { Mass (g) with } \\
2.5 \mathrm{~g} \mathrm{~cm}^{-3} \\
2.7 \mathrm{~g} \mathrm{~cm}^{-1}\end{array}$ & $\begin{array}{l}\text { Difference } \\
\text { from actual } \\
\text { mass (\%) }\end{array}$ \\
\hline $\begin{array}{l}\mathrm{Al}_{2} \mathrm{O}_{3} \text { sphere } \\
(\varnothing 22 \mathrm{~mm})\end{array}$ & 5575.28 & $3.75-3.9$ & 76.52 & $\begin{array}{l}191.30 \\
206.60\end{array}$ & $\begin{array}{l}-6.18 \\
+1.51\end{array}$ & 76.83 & $\begin{array}{l}192.06 \\
207.43\end{array}$ & $\begin{array}{l}-5.80 \\
+1.91\end{array}$ \\
\hline $\begin{array}{l}\mathrm{SiO}_{2} \text { sphere } \\
(\varnothing 20 \mathrm{~mm})\end{array}$ & 4188.8 & 2.5 & 80.01 & $\begin{array}{l}200.02 \\
216.03\end{array}$ & $\begin{array}{l}-1.73 \\
+6.00\end{array}$ & 80.18 & $\begin{array}{l}200.46 \\
216.50\end{array}$ & $\begin{array}{l}-1.51 \\
+6.19\end{array}$ \\
\hline $\begin{array}{l}\text { Calcite crystal } \\
(29.2 \mathrm{~g})\end{array}$ & 10900.5 & 2.68 & 84.02 & $\begin{array}{l}210.05 \\
226.85\end{array}$ & $\begin{array}{l}+3.19 \\
+10.87\end{array}$ & 85.49 & $\begin{array}{l}213.73 \\
230.83\end{array}$ & $\begin{array}{l}+4.90 \\
+12.58\end{array}$ \\
\hline
\end{tabular}

remains black. Due to the specific density of the used calcite crystal the grey-scale values are comparable to the scanned shells. During ontogeny the shell thickness increases in Nautilus, Spirula and ammonoids being the thinnest in early ontogenetic stages. In our example latest shell parts including the whole body chamber and the septa of the last whorl of the chambered phragmocone were selected with the threshold determined using the reference bodies. The earliest/thinnest juvenile shell parts are not within the selection due to lower grey-scale values. To overcome this problem we manually corrected the threshold to lower values and selected the remaining minor shell parts which may lead to a slight mass increase. Another agent that causes problems in exact determination of volumes in a 3-D data set is the partial volume effect (PVE).

The volume of a certain structure varies with different applied thresholds for segmentation. This problem is due to different voxel intensities seen as different grey scales in the resulting image depending on the attenuation effects of the scanned material the $\mathrm{x}$-rays are passing through. Attenuation of the x-rays mainly depends on the chemical composition of the material and to a lesser degree its density (Stock, 2006). $\mathrm{X}$-rays passing through $100 \%$ shell material or air result in white or black voxel. However, more than one material may be present within the space of one voxel, and since a voxel can only possess a single grey-scale value, the grey-scale value of the multiple materials is averaged together creating a gradient of black to white voxels at material boundaries. During the segmentation process the user must decide what percentage of this gradient is included in their final segmentation and runs the risk of including extra material or excluding material of interest depending on how the threshold is chosen (Fig. 5b-g). This PVE will therefore introduce an error that noticeably affects the accurate calculation of volume data (Table 3 for individually chosen threshold values). The percentage error in the mass calculation of the Nautilus shell using the calcite crystal as a reference body is reflecting this effect. As noted prior, assuming a shell density of $2.5 \mathrm{~g} \mathrm{~cm}^{-3}$, the $175 \mu \mathrm{m}$ scan has a percentage difference of $+4.9 \%$ and the $500 \mu \mathrm{m}$ scan a percentage difference of $65 \%$. In both cases the same reference body was used and in both data sets the selection of the innermost whorls through thresholding was impossible. Therefore the discrepancy between the calculated mass is partly due to the individual selection of material by the user of the inner whorl and, most significantly, to the error introduced by the PVE. Following this it is predicted that the discrepancy between the calculated mass of the shell based on a consistent reference body would decrease at higher resolutions. If increasingly higher resolution scans were taken of the Nautilus shell and the calcite crystal the difference between the calculated masses of each subsequent scan should diminish asymptotically. However, this needs to be tested.

Less problematic compared to a volumetric analysis is to measure distances and angles in 3-D data sets. Deviations that may occur are small and limited to $2-6$ voxel. In the case of the Nautilus shell (of $17 \mathrm{~cm}$ in diameter scanned with a resolution of $190 \mu \mathrm{m}$ ) the measured diameter, and all other measured distances, vary between $17 \mathrm{~cm} \pm 0.114 \mathrm{~cm}$, which is below $1 \%(0.67 \%)$. The model of the Nautilus was virtually cut along standardized axes (see above). Standardized distances were now measured every $10^{\circ}$. Using physical specimen cross-cut measuring is only possible every $180^{\circ}$ or at best $90^{\circ}$ after a second cross cut perpendicular to the first one. In comparison, with virtual clipping, measurements can be taken at every single degree for a precise description of ontogenetic changes. Therefore with virtual clipping more data for the same morphology or structure become available. According to Korn (2010) the most important ontogenetic trajectories used in the literature to describe coiled cephalopod conchs for Nautilus are shown in Figs. 6-7. These are the Whorl Width Index (WWI), Umbilical Width Index (UWI), Whorl Expansion Rate (WER), and the Conch Width Index (CWI). Additional features for species description become 


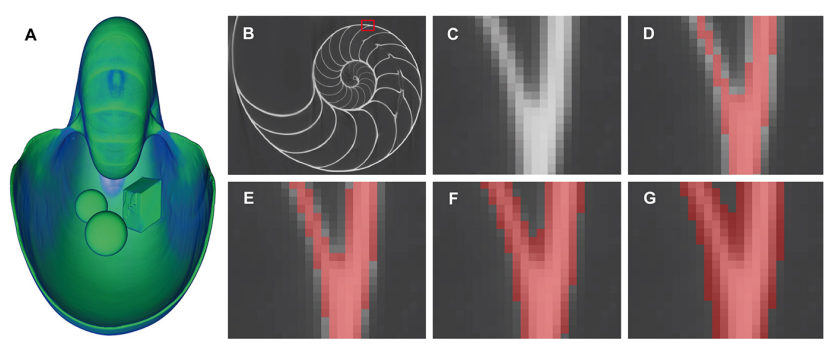

Figure 5. Partial volume effect (PVE) exemplified for the Nautilus pompilius shell (micro-CT scan, res. $175 \mu \mathrm{m}$ ). (A) image of the Nautilus shell scanned together with three reference bodies (phantoms); (B) orthoslice of the same shell; (C) close-up of (B) (red box) showing different grey scales; (D) selected shell material after adding a certain threshold value, which may underestimate the true shell volume; (E) one voxel was added to the selection shown in (D); (F) one voxel was added to the selection shown in $(\mathbf{E}) ;(\mathbf{G})$ one voxel was added to the selection shown in $(\mathbf{F})$, which may overestimate the true shell volume. The example demonstrates the importance of a correct threshold value for the material selection to produce a polygonal model with the highest approximation to the original shell.

available, e.g., septal spacing (Fig. 6e), siphuncle thickness and position, length of the juvenile shell (rotation angle to the nepionic constriction), and length of the body chamber.

For septal spacing we report a marked shift to lower values between septa 7 and 9 , indicating the moment of hatching in Nautilus according to Arnold et al. (2010). Between septa 9 and 30 the septal spacing remains more or less stable, resulting in a linear increasing total rotational angle. For the last few chambers the septal spacing again shows a marked shift to lower values (Fig. 6e), indicating the adult stage and growth stops of the animal, which are accompanied by the stop in shell growth causing septal crowding and a decreasing chamber volume (septal crowding; Collins and Ward, 2010; Fig. 6d).

In order to quantify and compare changes in chamber volumes between taxa (of extinct or extant cephalopods) at least one homologous structure is necessary. The protoconch is one possibility, representing the very first chamber. However, an easy comparison is difficult due to the broad morphological spectrum, different numbers of chambers between taxa and, in the case of fossil forms, different preservation. For example, the largest phragmocone chamber of the extant deep sea squid Spirula spirula is about $45 \mathrm{~mm}^{3}$, while the Nautilus pompilius protoconch exceeds that value with a volume of about $55 \mathrm{~mm}^{3}$.

Recently, Kerbl et al. (2013) applied micro-CT scanning together with contrast-enhancing substances for 3-D imaging of the soft-bodied cephalopod Euprymna. Based on 14 specimens these authors reconstructed the ontogenetic development of the nervous system of Euprymna, showing that ontogeny can also be analyzed from soft tissues using microCT technology.

\subsection{Nanofocus-computed tomography (nano-CT)}

Based on the observations of Brunke et al. (2008) and our own experiences the nano-CT fills the gap between micro$\mathrm{CT}$ and $\mathrm{SR} \mu \mathrm{CT}$ with respect to resolution and contrast properties of the produced images. Compared to a synchrotron facility set-up the access to a nano-CT is much easier. We ran several tests with the shell of Spirula spirula and the shell of a juvenile ?Cadoceras. Due to the high-resolution scans the PVE will be negligible and is not discussed. Here we describe minute structures of the shell of Spirula that become visible, while the nano-CT data for the juvenile ?Cadoceras will be compared with SR $\mu \mathrm{CT}$ - and micro-CT-derived images in the following chapter. Due to the high resolution $(8.7 \mu \mathrm{m}), 2-\mathrm{D}$ measurements are highly precise and since the PVE is minor the same holds true for volumes. Quantification of morphological characters and volumes as well as ontogenetic changes back to the very first chamber (protoconch) with its $1-2 \mu \mathrm{m}$ thick shell wall including buoyancy calculation become available with the necessary precision.

In contrast to surface scanning or $60 \mu \mathrm{m}$ resolution microCT scans the high-resolution scans of the nano-CT enable the recognition of very minute conch features like the pillar zone of the siphuncle, attachment scars on the inner surface of every chamber, and minute crenulation of the shell surface resulting from the attachment of the soft body along the outer surface of the shell (Fig. 8c). Reticulate patterns disappear in the ventral area and along the margin of the aperture (Fig. 8a), where the soft body obviously was not attached to the shell.

Applied to the extinct ammonoids, exact morphological data become available for the description of features of the ammonitella, the ammonite hatchling shell, or muscle attachment sites of the soft body to the shell wall (Doguzhaeva and Mutvei, 1996; Shigeta, 1993). Morphology of the ammonitella was used to distinguish between major ammonoid groups based on protoconch size and shape, fixator length and position, position of the siphuncle, length/angle of the ammonitella and the nepionic constriction. Internal structures like septal and conch wall thickness or siphuncle thickness of the ammonitella were achieved by cross sections. External shell features like crenulation as shown for Spirula (Fig. 9), which are also present on juvenile gastropod shells (Bandel, 1982), can be traced and used for the discussion if ammonoids had an internal or external shell (Doguzhaeva and Mutvei, 1996). However, the high scan resolution makes the nano-CT a useful tool for microfossils like Foraminifera or Ostracoda with complex internal shell structures (Briguglio et al., 2011; Görög et al., 2012; Hohenegger and Briguglio, 2012). 

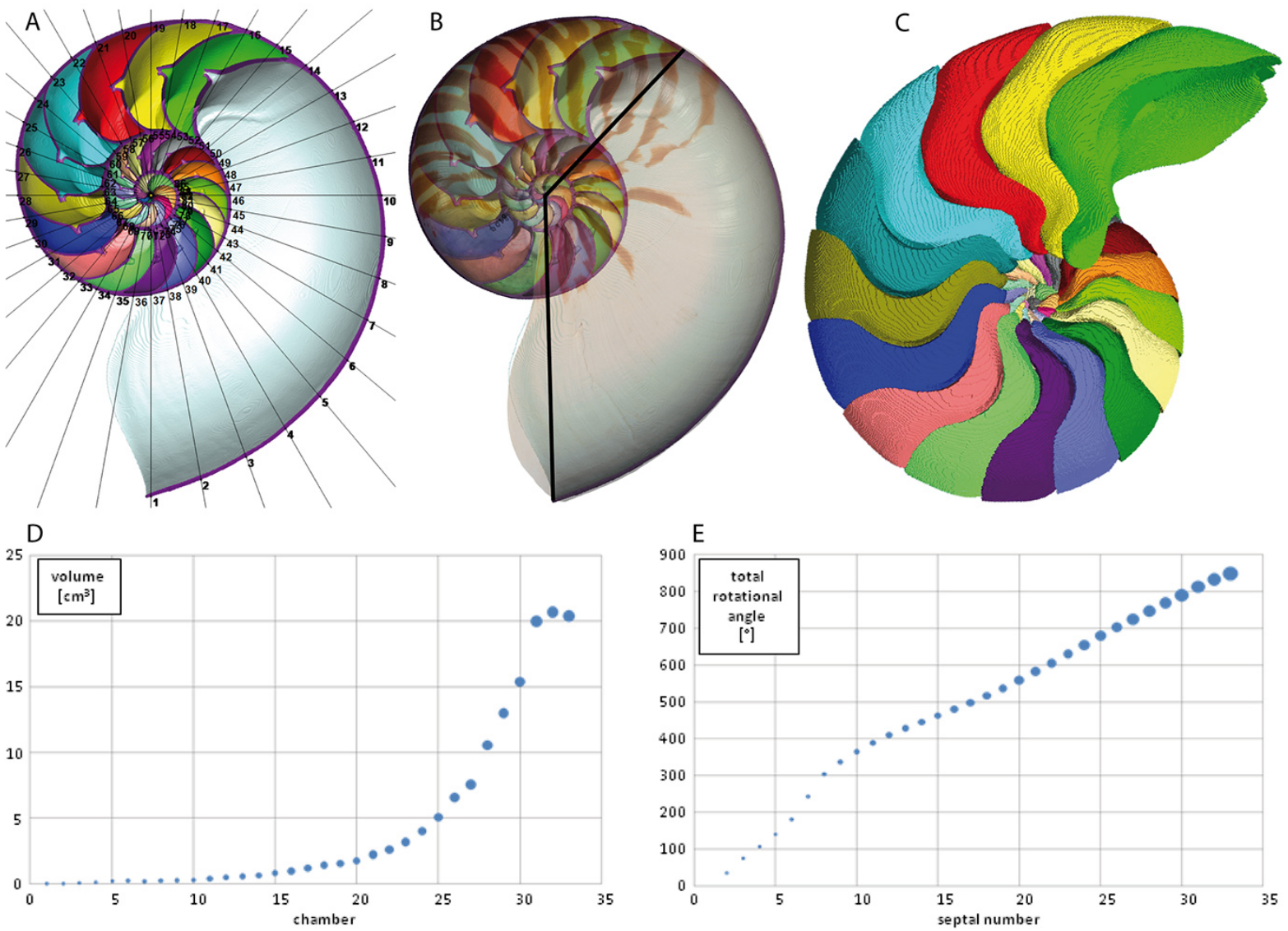

Figure 6. Nautilus pompilius from the Philippines, $17 \mathrm{~cm}$ in diameter. (A) median section with a $10^{\circ}$ grid and markers necessary for the description of the conch morphology-like diameter (dm), umbilical width (uw) or whorl height (wh); note: usually data are obtained starting from the adult shell (aperture); (B) transparent photography of the shell, overlying the image of (A); the two black bars document the body chamber length, which is $136^{\circ}$; (C) phragmocone without body chamber and shell material, same orientation as in (A) and (B); each chamber volume was separately segmented; (D, E) ontogenetic trajectories of different conch parameters with: (D) chamber volume in $\mathrm{cm}^{3}$, which is important for the buoyancy calculation; (E) total rotational angle as an indicator of continuously increasing or decreasing septal spacing. Increasing size of the blue dots represents ontogeny (D, E); note: usually obtained values represent the course of ontogeny ((A-C): modified after Hoffmann and Zachow, 2011).

\subsection{Synchrotron radiation based micro-computed tomography $(\mathrm{SR} \mu \mathrm{CT})$}

Due to the very high resolution and the precision of SR $\mu \mathrm{CT}$ scans this technique is of increasing interest for very small specimens and delicate structures (Prymak et al. (2005) quantified the shell thickness of a 120 hour-old gastropod shell) even if preserved within surrounding rocks. Recently, Kruta et al. (2011) were able to present a reconstruction of a full buccal apparatus, including the radula, of a Mesozoic ammonite (Baculites, Upper Cretaceous) using SR $\mu \mathrm{CT}$ technology, where most of the single radula tooth elements had a size of $500 \mu \mathrm{m}$. In order to compare the results of an SR $\mu \mathrm{CT}$ scan with other CT techniques we used three different juvenile ammonites of ?Cadoceras sp. scanned at the APS synchrotron facility in Chicago (USA). All specimens come from the same locality and have the original aragonitic shell preserved. The reconstructed images of the micro-CT with a low SNR result in relatively poor contrast in the grey-scale images. The septa of the first specimen appear thicker than expected for this ontogenetic stage (Fig. 10a) and lead to the unproven assumption that some other material with similar absorption properties has covered the primary shell material. The images from the nano-CT, with a sharper contrast, reveal secondary calcite crystals, with pronounced growth in the apertural direction (Fig. 10b) in the second specimen. Due to the precision of the high-resolution scan even the nepionic constriction (Fig. 10b and c; green arrow), which indicates the moment of hatching in ammonoids, is visible. The sharpest result with the highest contrast was achieved using SR $\mu \mathrm{CT}$. The images show a secondary layer of calcite crystals on the inner shell surface of the third specimen. The amount of crystal growth differs between the three different specimens used in our study. The documented crystal growth 

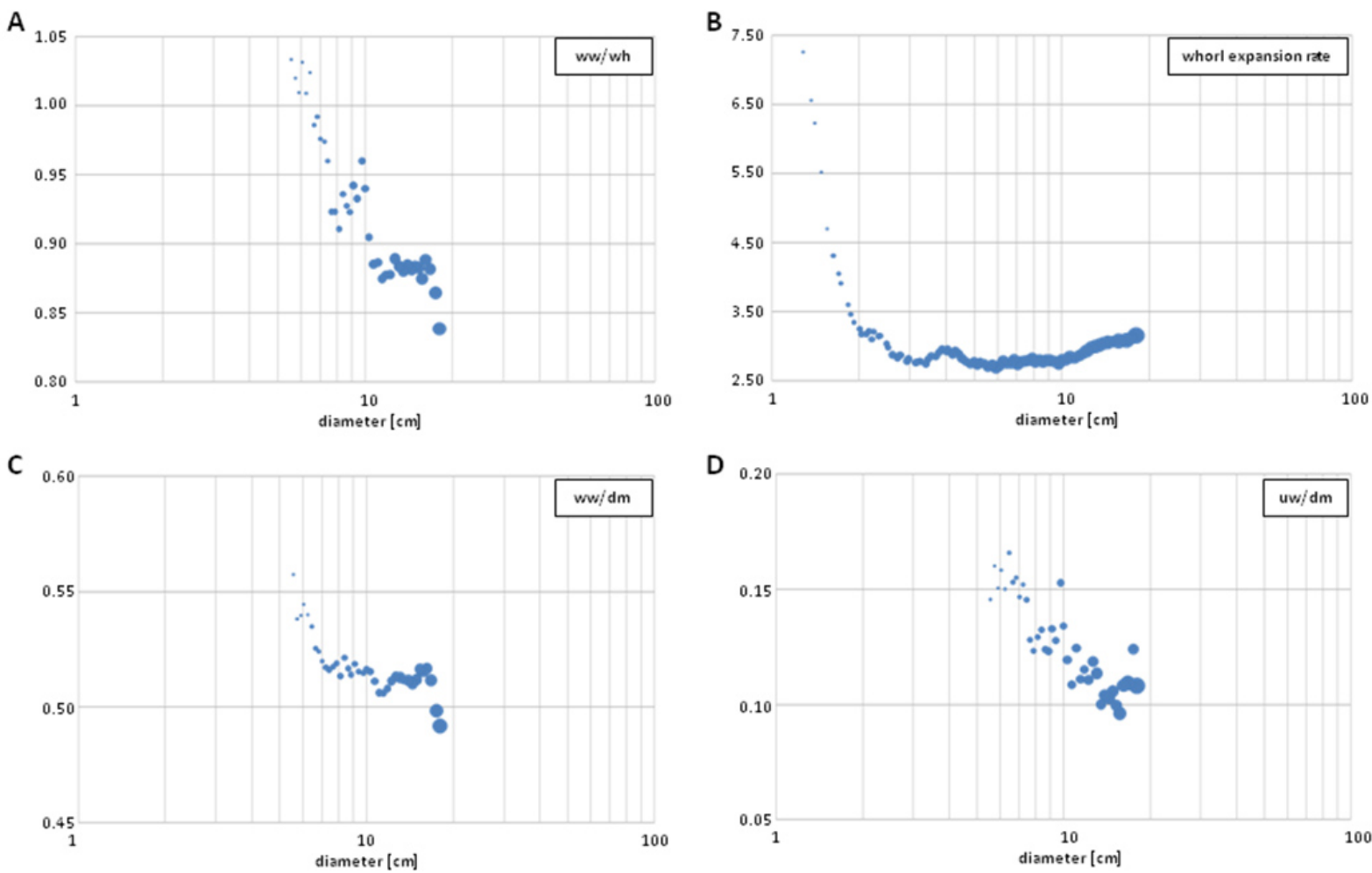

Figure 7. Nautilus pompilius ontogenetic trajectories of different conch parameters for the same specimen shown in Fig. 6. According to Korn (2010) main conch features are: diameter (dm), umbilical width (uw), whorl height (wh), and whorl width (ww), and for heteromorph ammonoids the whorl interspace (wi) as well. Ratios derived from primary data (e.g., UWI, CWI, WWI and WER) can be plotted for comparison in a logarithmic plot against conch diameter. (A) Whorl width index (ww/wh); (B) whorl expansion rate (WER); (C) conch width index (ww/dm); (D) umbilical width index (ww/dm). Increasing size of the blue dots represents ontogeny.

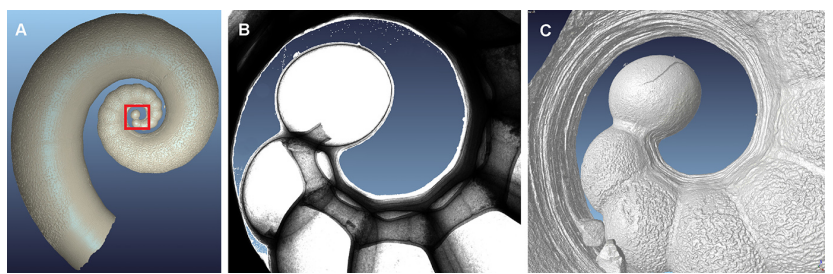

Figure 8. Nano-CT scan (res. $1.8 \mu \mathrm{m}$ ) of Spirula spirula from the Canary Islands (1.6 cm in diameter). (A) isosurface showing the distribution of the reticulate pattern, which is not present in the aperture and the ventral area. The red box encloses the earliest chamber built within the egg (protoconch). (B) X-ray rendering, close-up of (A) with the protoconch and the organic strand (siphuncle) that connects all chambers of the shell; (C) surface rendering of the same area as in $(\mathbf{B})$, surface view with the reticulate pattern and the ventral area of the first whorl with growth lines of the "ventral rib" pointing to the solid base of the organic membrane (compare Warnke and Boletzky, 2009).

has to be taken into account during the subsequent segmentation process, where the inclusion of crystals in the shell material should be avoided; otherwise a buoyancy calculation will fail. Our observation of secondary calcite crystals
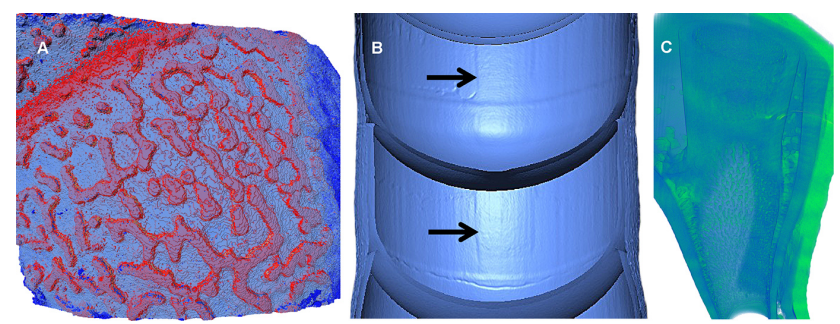

Figure 9. The same Spirula spirula specimen as in Fig. 8. (A) close-up of the reticulate surface pattern (nano-CT res. $1.8 \mu \mathrm{m}) ;(\mathbf{B})$ nano-CT image (res. $1.8 \mu \mathrm{m}$ ) of the inner surface of two successive chambers showing a rectangular dorsal attachment scar (arrows); (C) $\mathrm{SR} \mu \mathrm{CT}$ image (res. $0.74 \mu \mathrm{m}$ ) of the siphuncle and ventral part of the shell, showing the light-green pillar zone all along the calcareous tube in the lower half of the image; orientation of the image with the top in the growth direction.

within the chambers of hollow ammonites with their original shell (aragonitic nacre) preserved is interesting for geochemists too. The crystals are up to ten times thicker than the original shell material and contain different isotope and trace element signatures compared to the ammonoid nacre (Fig. 10f, white arrow). Since the standard procedure for 


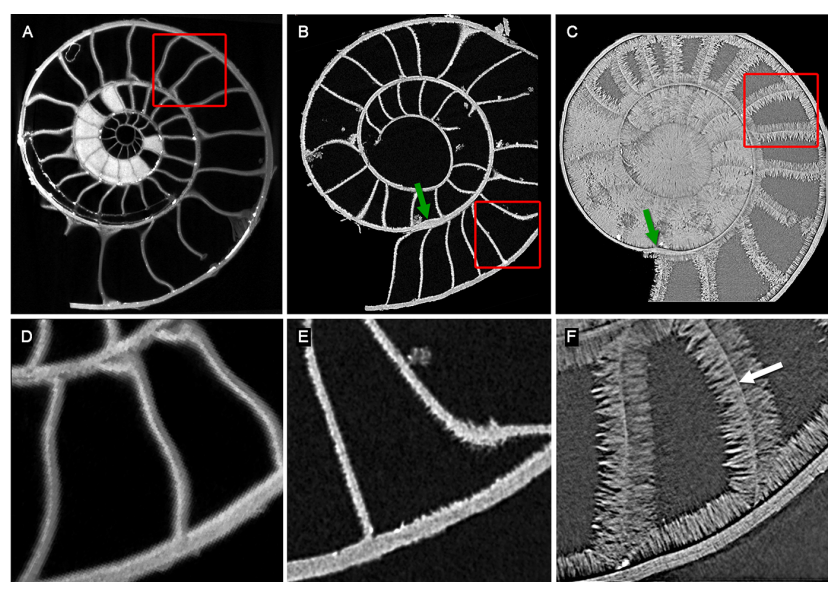

Figure 10. Three juvenile Cadoceras sp. specimens from the Upper Jurassic (Callovian) of Russia. (A, D) micro-CT scan with a resolution of $7.5 \mu \mathrm{m}$; (D) close up of (A) (red box), the original shell material cannot be distinguished from secondary calcite crystals that cover the inner surface of the conch wall and septa; $(\mathbf{B}, \mathbf{E})$ nano-CT scan with a resolution of $1.0 \mu \mathrm{m}$; (B) nepionic constriction indicated by green arrow; (E) close up of (B) (red box), some secondary calcite crystals become visible and the former smooth appearing surface turns into a rough one; $(\mathbf{C}, \mathbf{F}) \mathrm{SR} \mu \mathrm{CT}$ with a resolution of $0.74 \mu \mathrm{m}$; (C) nepionic constriction indicated by green arrow; (F) close up of (C) (red box), this specimen shows a rather heavy infill with secondary calcite crystals; however, the original shell (e.g., thin septa) is distinguishable (white arrow).

isotopic analysis contains the process of sample powdering this means that a mixed signal will be obtained that does not represent the sole isotope signal of the ammonoids ambient seawater during lifetime. Due to the assumed early diagenetic growth of secondary calcite crystals within the ammonoids shell these will record a bottom water signal that will hamper a correct paleo-seawater temperature reconstruction (see also Marshall, 1981). A sufficient resolution and SNR to distinguish between primary shell and secondary calcite was only possible with $\mathrm{SR} \mu \mathrm{CT}$ technology.

\subsection{Magnetic Resonance Imaging (MRI)}

MRI has been rarely applied to extant (Sepia in Quast et al., 2001; and in Ziegler et al., 2011; Lolliguncula in Gozansky et al., 2003; Loligo in Mooney et al., 2010) or fossil cephalopod material (belemnites in Mietchen et al., 2005, 2008). In the case of belemnites (ten armed coleoids) this technique elucidated paleopathological and paleoecological questions (Fig. 11). Measurements were made with a BRUKER ${ }^{\circledR}$ Advance NMR spectrometer. The images of the pathological belemnite rostra were recorded using a 3-D spin-echo imaging sequence (Mietchen et al., 2005, Table 1). The total data acquisition time depends on the sample's signal strength, but in our case was not less than $18 \mathrm{~h}$. In fossil material hydrogen nuclei (protons) can be used as agents for MRI. Since wa-

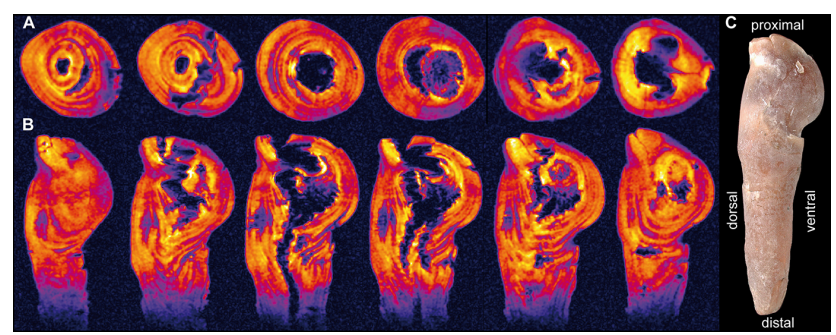

Figure 11. Hibolithes jaculoides from the Lower Cretaceous (Hauterivian) of northwestern Germany (PB251 Coll. H. Keupp; $4.2 \mathrm{~cm}$ long). This specimen shows a pathology due to a parasite encapsulated within the shell secreting mantle epithelia during early ontogeny. (A) Images of an MRI scan of the cross section from distal to proximal (left dorsal, right ventral); (B) images of the same MRI scan of the longitudinal section (same orientation as in $\mathbf{C}$ ); rows (A) and (B) show the internal malformation of the rostral skeleton; (C) specimen in lateral view. (Modified from Mietchen et al., 2005.)
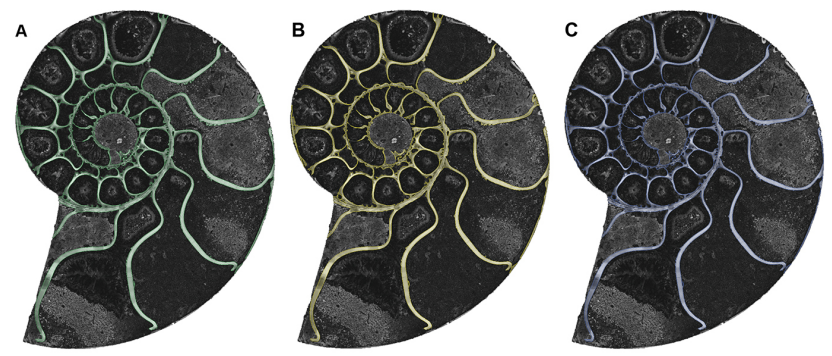

Figure 12. 2-D scan image of a cut and polished Argonauticeras sp. along the median line from the Lower Cretaceous (Albian) of Madagascar (diameter $=9.5 \mathrm{~cm})$. (A) "growth model" - selected shell material in green with one pixel added to the complete outline seen in (B); (B) selected shell material in yellow obtained after the application of a manually chosen threshold for selection; $(\mathbf{C})$ "shrink model" - selected shell material in blue with one pixel subtracted from the complete outline seen in $(\mathbf{B})$, pixel size for a $600 \mathrm{dpi}$ scan $=42.3 \mu \mathrm{m}$, difference from (A) to (B) and (B) to $(\mathbf{C})=9.5 \% \mathrm{cp}$. with Fig. 5 for the PVE; note that the "voxel size" obtained is not isotropic due to differing distances between each slice, and even in the "growth model" (A) not all shell material was selected due to low grey values; an error of about $20 \%$ for a volume calculation (shell or chambers) is suspected.

ter is the contrast agent for MRI, this non-invasive technique may become an important tool for 3-D reconstructions of dissolved aragonite shells within rocks. The space between internal mold and surrounding rocks can be flooded with water using a vacuum for one or two weeks. MRI provides a better edge resolution and finer details compared to CT scans of comparable resolution. These properties can be improved by using contrast agents such as gadodiamide solution or other substances with paramagnetic properties that decrease or increase the local MRI signal (Clark et al., 2004; Ziegler et al., 2011). This may be of special interest for species with a highly complex morphology, which are normally hard to 
mold with putty, like the heteromorph ammonite Nipponites. Problems may occur if liquid penetration into unconnected voids is limited by the porosity and permeability of the encapsulating sediment. Bubbles cause artifacts on the images and have to be extracted from the structure of interest before scanning takes place or needs to be removed virtually during the post-processing step.

\section{Summary}

Our investigations demonstrate that non-invasive imaging methods are a powerful tool to for example perform buoyancy calculation for chambered cephalopods. Important prerequisites in order to perform an exact determination of volumes and areas (chamber, shell and septum) are: highest possible resolution, good SNR, reconstruction algorithms that distinguish between structure and normal distributed noise, reduction of scan artifacts and the application of the QCT approach using adequate phantoms for minimizing the PVE. It shows that engineering 3-D software packages (e.g., Polyworks, Avizo, etc.) can be used after scanning to improve the understanding of paleobiological aspects of several fossil groups not only ammonoids. Changes in chamber volumes and volumes of the septa can be traced and compared with other morphological changes in order to detect some hitherto unknown relationships. For Nautilus we performed successfully, for the first time using non-invasive methods, a buoyancy calculation to support and validate what was already known: Nautilus can float (Fig. 4); i.e., buoyancy is sufficient in compensating shell weight and the weight of the soft body. This method is therefore proven to be transferrable to the extinct group of ammonoids for selected species with implications on floating behavior. Dynamic processes, e.g., water currents or motion (swimming activities, jet propulsion) undoubtedly influences buoyancy. However, here we address the question whether the shell can provide sufficient values for buoyant force to support the weight of the animal and the shell.

From the authors' view it seems necessary to give some annotations for 3-D reconstructions of volumes (chamber, shell, septa, and siphuncle) derived from invasive methods like serial grinding tomography. The most important thing is to recognize that the PVE is also present in grinding tomography images (Fig. 12), but this has not yet been taken into account (see Naglik et al., 2014 and Pascual-Cebrian et al., 2013). A second issue is the non-isotropic voxel size produced during grinding tomography. Non-isotropic voxel size results from different distances between the single slices and will complicate potential error calculations as the error (due to PVE) will be of different impacts in the different planes of the image stack. The spatial resolution for the serial grinding approach depends on pixel size, slice width, contrast (SNR) and modulation transfer function.
As exemplified above, the different non-invasive methods have disadvantages and advantages. Surface scans can be used for a sufficient description of the outer shell morphology using 2-D measurements and ratios (Korn, 2010). In the case of isolated objects like an ammonoid shell (free from surrounding rock material) the volume of the whole shell can be calculated from surface scan data. In our case surface scans were not only used for the description of the morphology of cephalopod shells but also to obtain volume data from a calcite crystal that was subsequently used as a reference body. The volume was obtained by high-resolution surface scanning $(16 \mu \mathrm{m})$ and not by CT scanning because surface scanning does not depend on material properties such as density or composition, but we are aware that shiny surfaces can complicate the scanning process. Besides the exact determination of 3-D values the application of non-invasive methods will provide researchers with precise 2-D morphological information on external and internal features.

The species concept in paleontology is purely based on the morphology of preserved hard parts. Due to their accretionary growth conserving ontogenetic changes molluscs are ideal candidates to study ontogenetic change, intraspecific variability, and macro-evolutionary patterns. Ammonoid species were usually differentiated from each other utilizing a static ("Linnean") rather than a dynamic ("Darwinian") approach both representing the morpho-species concept. The static method does not account for intraspecific variation, co-variation, and ontogenetic changes. Many species were thus validated on the basis of more or less subtle morphological differences of the adult stage. During the last decades the way of species description has changed significantly, regarding ontogeny as well as the use of intraspecific variability analyses. More recent studies of Mesozoic ammonoids document a wide intraspecific variability in conch parameters and ornamentation, when a sufficient amount of specimens were available (Dagys and Weitschat, 1993; De Baetes et al., 2013; Monnet et al., 2010). With noninvasive imaging methods more data for certain morphologies are achieved compared to the standard procedure. Standard procedure here means presenting a single set of data for one specimen or if the specimen was cross cut data for every $180^{\circ}$. Skilled technicians could do a second cut in order to obtain data for every $90^{\circ}$. Cutting plane needs to be polished, surface scanned, traced (recognition of structure) and aligned. All steps are not automatized and time consuming. However, enormous improvement has also been done towards a more precise description of intraspecific variability and ontogenetic changes with the application of invasivetechniques (Kraft et al. 2008, Korn, 2012). Nevertheless, non-invasive methods provide additional information about external features, e.g., ornamentation irregularities, and internal morphological structures (e.g., septal spacing, thickness, and shape, suture line, position and geometry of muscle attachment site, conch wall thickness, position and diameter of the siphuncle, and from the ammonitella the dimension 
of the protoconch, caecum, ammonitella angle, length of the fixator among others) become available by keeping the fossil undamaged. Therefore, it is possible to apply these methods to study very rare material, such as holo-, para- or neo-types. The suture line for example is the result of the connection of the septa with the inner surface of the conch wall. Juvenile and adult suture lines have been used to distinguish between major ammonoid taxa (Schindewolf, 1961-1968). By the application of non-invasive methods the tracing of the ontogenetic development of the suture line becomes easier. This holds true also for a variety of features changing throughout ontogeny. Another important feature is the connection site of the soft body to the shell - the so-called attachment scars. As far as we know, no study of ontogenetic changes of attachment scars is available for cephalopods (Fig. 9b). Significant changes in these scars can be compared with changes in morphology. This knowledge is crucial for functional morphology and/or paleobiological reconstructions. The detailed morphological description of shapes and the increased number of available features for species characterization enable subsequent cladistic analyses to test existing phylogenetic hypotheses of the studied groups. Ontogenetic changes of external (UWI, CWI, WWI and WER; Fig. 7) and internal features (chamber volume, septal spacing; Fig. 6) are documented herein for a single shell of an extant Nautilus pompilius. However, our presented application shows that with a reasonable amount of specimens at hand non-invasive methods are suitable for improving palaeontological species definition by taking intraspecific variability into account. For example, the ammonoid taxon Svalbardiceras shows a high morphological plasticity (Weitschat, 2008), while other taxa show only very small variations in their shell morphology, like most of the lytoceratids (Hoffmann, 2010).

Due to the low resolution but fast scanning, medical-CT scanners can aid in the search for suitable material in larger rock samples and prevent that material from being destroyed by a hammer stroke. Images derived from medical CTs (resolution of 2 to $0.5 \mathrm{~mm}$ ) are not suitable for a precise description of morphologies or the depiction of thin internal structures like ammonoid septa. Micro-CT scanners have a reasonable resolution. Sometimes devices are equipped with two $\mathrm{x}$-ray tubes (macro and micro) with a resolution down to about $2 \mu \mathrm{m}$. Issues of medical- and micro-CTs are low SNR and scan artifacts. Nano-CTs represent in our case the best solution in terms of scan quality and expenses for scans. The main advantage lies here in the detection of shell features that are otherwise invisible, but the specimen size is limited by small sample chambers. While medical-, micro- and nanoCTs use polychromatic $\mathrm{x}$-ray beams, the $\mathrm{SR} \mu \mathrm{CT}$ technology uses monochromatic beams. SR $\mu \mathrm{CT}$ is the first choice for investigating very thin structures like septa of juvenile chambered cephalopods ( $\sim 2-5 \mu \mathrm{m}$ thick), but some effort has to be kept in mind in order to get scanning time at such a facility; a written proposal is needed. In contrast to tomography, MRI is very time consuming, with a limited resolution (about $40 \mu \mathrm{m}$ ), and has rarely been applied to paleontological research. However, potential for application is seen in fossils preserved as molds where the rock conserved the gap that was originally filled with the shell. As stated above, by filling the gap with a contrast agent the complete shell with its external (imprint with ornamentation) and internal (mold) features will become available.

With a broader application of the non-invasive methods used here, the understanding of intraspecific variability (disparity) is improved and supports a critical revision of ammonoid paleodiversity and the phylogenetic relationships of ammonoid species. Based on well-preserved material and the non-invasive approach, precise buoyancy calculations (see above) can shed new light on the discussion about the swimming abilities and paleobiology of ammonoids (Westermann, 1993). Furthermore, there exists a century-old debate concerning the main function of the complexly fluted ammonite septa (summarized in Hoffmann, 2010). Hitherto, the function was mainly discussed on the basis of mathematical models, and two major interpretations arose. One postulates a mechanical strengthening of the shell against hydrostatic pressure, while the other favors physiological reasons (pumping out and refilling of chamber liquid). During the last two decades two attempts were made to solve this problem with the help of mathematical algorithms and computers (Daniel et al., 1997; Hassan et al., 2002), resulting in opposite results. Our applications show a potential in 3-D models obtained from original fossil material to contribute greatly to this discussion.

To sum up, our approach requires high-resolution scan data for a precise determination of volumes. The minimum prerequisite is a resolution twice the dimensions of the smallest structure of interest. We demonstrated that higher resolution minimizes the PVE, i.e., the precision of the volume calculation increases. With a reasonable resolution $(\mathrm{SR} \mu \mathrm{CT})$ this method is also applicable for microfossils, e.g., foraminifera or radiolarian. A good SNR allows the segmentation of delicate structures. A low SNR results from materials of similar chemical composition. Therefore, calcareous sedimentary infill or secondary calcite covering of a carbonatic shell will hamper the differentiation between shell and inorganic material. Any metal (e.g., pyrite) will completely absorb the x-rays and results in areas that contain no structural information and make a reconstruction impossible. The highest resolution mode of a certain device will also result in images with a low SNR. At the moment our approach, the precise calculation of volumes (shell and phragmocone chambers), is limited by the fossil record due to the need for hollow preserved material. In the case of a low SNR but significant optical differences between shell and surrounding rocks the grinding tomography approach (physical optical tomography) represents the method of choice. Fossils with a low SNR to their surroundings (fossils in amber) can properly be visualized by the application of highresolution monochromatic phase contrast SR $\mu \mathrm{CT}$ (Sutton, 
2014). However, sooner or later improved image enhancement algorithms will overcome this limitation and allow scanning and successful reconstruction of data derived from devices using polychromatic $\mathrm{x}$-ray beams. The identification of organic matter is possible with MRI as long as enough reactive substances are present and the structures of interest are larger than $80-100 \mu \mathrm{m}$. Broken or deformed shells due to high pressure as well as specimens with the shell already dissolved (internal molds) are not suitable for this approach. However, potential application can be seen in virtual retrodeformation of fossils. Application of x-ray diffraction tomography will aid in the recognition of the original crystal pattern of the shell, allowing a more accurate detailing of alteration processes.

Acknowledgements. The authors are grateful to F. Fusseis (Edinburgh, United Kingdom), X. Xiao (Argonne, USA), G. Fritsch (Kleintierklinik, Düppel, Berlin, Germany), J. Goebbels working group (Bundesanstalt für Materialforschung und -prüfung, Berlin, Germany), L. Heuser and W. Weber (Universitätsklinikum Knappschaftskrankenhaus Bochum) for several CT scannings, D. Mietchen (Fraunhofer Institute, St. Ingberg and Saarbrücken, Germany) for biomedical engineering (IBMT), and S. Ingbert (Faculty of Physics and Mechatronics, University of the Saarland, Saarbrücken, Germany) for MRImaging. A. Ziegler provided information about MRImaging. M. Ehlke (Zuse Institut Berlin) helped us with several problems concerning the CT-data analyses. V. Mitta (Moscow) and J. Gründel (Freie Universität Berlin, Germany) donated small juvenile ammonoids and Y. Shigeta (National Museum of Nature and Science, Department of Geology and Paleontology, Division of Paleoenvironment and Paleoecology, Tokyo, Japan) loaned the hollow specimen of Gaudryceras presented in this study. RH acknowledges the financial support of the DFG (project no. HO 4674/2-1).

Edited by: E. J. Javaux

\section{References}

Adams, J. E.: Quantitative computed tomography, Eur. J. Radiol., 71, 415-424, doi:10.1016/j.ejrad.2009.04.074, 2009.

Anderson, P. S. L., Bright, J. A., Gill, P. G., Palmer, C., and Rayfield, E. J.: Models in palaeontological functional analysis, Biol. Lett., 8, 119-122, doi:10.1098/rsbl.2011.0674, 2012.

Arnold, J. M., Landman, N. H., and Mutvei, H.: Development of the embryonic shell of Nautilus, in: Nautilus - The biology and paleobiology of a living fossil, reprint with additions, edited by: Saunders, W. B. and Landman, N. H., Topics in Geobiology, Springer Netherlands, 373-400, 2010.

Bandel, K.: Morphologie und Bildung der frühontogenetischen Gehäuse bei conchiferen Mollusken, Facies, 7, 1-198, doi:10.1007/bf02537225, 1982.

Baruchel, J., Buffiere, J.-Y., Cloetens, P., Di Michiel, M., Ferrie, E., Ludwig, W., Maire, E., and Salvo, L.: Advances in synchrotron radiation microtomography, Scripta Mater., 55, 41-46, doi:10.1016/j.scriptamat.2006.02.012, 2006.
Bates, K. T. and Falkingham, P. L.: Estimating maximum bite performance in Tyrannosaurus rex using multi-body dynamics, Biol. Lett., 8, 660-664, doi:10.1098/rsbl.2012.0056, 2012.

Bonse, U. and Busch, F.: X-ray computed microtomography ( $\mu \mathrm{CT})$ using synchrotron radiation (SR), Prog. Biophys. Mol. Bio., 65, 133-169, 1996.

Briguglio, A., Metscher, B., and Hohenegger, J.: Growth rate biometric quantification by $\mathrm{x}$-ray microtomography on larger benhic Foraminifera: three-dimensional measurements push nummulitids into the fourth dimension, Turkish J. Earth Sci., 20, 683-699, doi:10.3906/yer-0910-44, 2011.

Brunke, O., Brockdorf, K., Drews, S., Müller, B., Donath, T., Herzen, J., and Beckmann, F.: Comparison between x-ray tube-based and synchrotron radiation-based $\mu \mathrm{CT}$, Proc. SPIE 7078, Developments in X-Ray Tomography VI, 70780U, 1-12, doi:10.1117/12.794789, 2008.

Callaghan, P. T.: Principles of nuclear magnetic resonance microscopy, Oxford University Press, Clarendon, 1991.

Clark, N. D. L., Adams, C., Lawton, T., Cruickshank, A. R. I., and Woods, K.: The Elgin marvel: using magnetic resonance imaging to look at a mouldic fossil from the Permian of Elgin, Scotland, UK, Magn. Reson. Imaging, 22, 269-273, doi:10.1016/j.mri.2003.09.006, 2004.

Collins, D., and Ward, P. D.: Adolescent growth and maturity in Nautilus, in: Nautilus - The biology and paleobiology of a living fossil, reprint with additions, edited by: Saunders, W. B. and Landman, N. H., Topics in Geobiology, Springer Netherlands, 421-432, 2010.

Dagys, A. S. and Weitschat, W.: Extensive intraspecific variation in a Triassic ammonoid from Siberia, Lethaia, 26, 113-121, doi:10.1111/j.1502-3931.1993.tb01801.x, 1993.

Daniel, T. L., Helmuth, B. S., Saunders, W. B., and Ward, P. D.: Septal complexity in ammonoid cephalopods increased mechanical risk and limited depth, Paleobiology, 23, 470-481, 1997.

Davis, G. R. and Elliott, J. C.: Artefacts in X-ray microtomography of materials, Mater. Sci. Tech., 22, 1011-1018, doi:10.1179/174328406x114117, 2006.

De Baets, K., Klug, C., and Monnet, C.: Intraspecific variability through ontogeny in early ammonoids, Paleobiology, 39, 75-94, doi:10.1666/0094-8373-39.1.75, 2013.

Doguzhaeva, L. A. and Mutvei, H.: Attachment of the body to the shell in ammonoids, in: Ammonoid paleobiology, edited by: Landman, N. H., Tanabe, K., and Davis, R. A., Topics in Geobiology, 13, Plenum Press, New York, 43-63, 1996.

Drews, S., Beckmann, F., Herzen, J., Brunke, O., Salmon, P., Friess, S., Laib, A., Koller, B., Hemberger, T., Müller-Gerbl, M., and Müller, B.: Comparative micro computed tomography study of a vertebral body, Proc. SPIE 7078, Developments in X-Ray Tomography VI, 70780C, 1-14, doi:10.1117/12.793815, 2008.

Falkingham, P. L.: Acquisition of high resolution 3-D models using free, open-source, photogrammetric software, Palaeontol. Electron., 15, 1-15, 2012.

Friis, E. M., Crane, P. R., Pedersen, K. R., Bengtson, S., Donoghue, P. C. J., Grimm, G. W., and Stampanoni, M.: Phase-contrast Xray microtomography links Cretaceous seeds with Gnetales and Bennettitales, Nature, 450, 549-552, doi:10.1038/nature06278, 2007. 
Görög, Á., Szinger, B., Tóth, E., and Viszkok, J.: Methodology of the micro-computer tomography on Foraminifera, Palaeontol. Electron., 15, 1-15, 2012.

Gozansky, E. K., Ezell, E. L., Budelmann, B. U., and Quast, M. J.: Magnetic resonance histology: in situ single cell imaging of receptor cells in an invertebrate (Lolliguncula brevis, Cephalopoda) sense organ, Magn. Reson. Imaging, 21, 10191022, doi:10.1016/S0730-725X(03)00215-7, 2003.

Gray, F.: Pulse code communication, March 17, 1953, United States Patent no. 2,632,058, 1953

Hassan, M. A., Westermann, G. E. G., Hewitt, R. A., and Dokainish, M. A.: Finite-element analysis of simulated ammonoid septa (extinct Cephalopoda): septal and sutural complexities do not reduce strength, Paleobiology, 28, 113-126, doi:10.1666/00948373(2002)028<0113:feaosa >2.0.co;2, 2002.

Herbert, M. H., Jones, C. B., and Tudhope, D. S.: Threedimensional reconstruction of geoscientific objects from serial sections, Visual Comput., 11, 343-359, doi:10.1007/bf01909875, 1995.

Hoffmann, R.: New insights on the phylogeny of the Lytoceratoidea (Ammonitina) from the septal lobe and its functional interpretation, Rev. Paleobiol., 29, 1-156, 2010.

Hoffmann, R. and Zachow, S.: Non-invasive approach to shed new light on the buoyancy business of chambered cephalopods (Mollusca), IAMG 2011, 506-516, doi:10.5242/iamg.2011.0163, 2011.

Hoffmann, R., Zachow, S., Fusseis, F., and Korn, D.: Quantitative morphology using X-ray computed tomography and the species concept in palaeontology: a case study from cephalopods, Terra Nostra, 2012, 80-81, 2012.

Hohenegger, J. and Briguglio, A.: Axially oriented sections of nummulitids: a tool to interpret larger benthic foraminiferal deposits, J. Foramin. Res., 42, 134-142, doi:10.2113/gsjfr.42.2.134, 2012.

Hurum, J. H.: Three-dimensional reconstruction in palaeontology, GFF, 118, p. 60, doi:10.1080/11035899609546345, 1996.

Kerbl, A., Handschuh, S., Nödl, M.-T., Metscher, B., Walzl, M., and Wanninger, A.: Micro-CT in cephalopod research: Investigating the internal anatomy of a sepiolid squid using a non-destructive technique with special focus on the ganglionic system, J. Exp. Mar. Biol. Ecol., 447, 140-148, doi:10.1016/j.jembe.2013.02.022, 2013.

Klug, C., Riegraf, W., and Lehmann, J.: Soft-part preservation in heteromorph ammonites from the Cenomanian-Turonian Boundary Event (OAE 2) in north-west Germany, Palaeontology, 55, 1307-1331, doi:10.1111/j.1475-4983.2012.01196.x, 2012

Korn, D.: A key for the description of Palaeozoic ammonoids, Foss. Rec., 13, 5-12, doi:10.1002/mmng.200900008, 2010.

Korn, D.: Quantification of ontogenetic allometry in ammonoids, Evol. Dev., 14, 501-514, doi:10.1111/ede.12003, 2012.

Korn, D. and Vöhringer, E.: Allometric growth and intraspecific variability in the basal Carboniferous ammonoid Gattendorfia crassa Schmidt, 1924, Paläont. Z., 78, 425-432, doi:10.1007/bf03009233, 2004.

Kraft, S., Korn, D., and Klug, C.: Patterns of ontogenetic septal spacing in Carboniferous ammonoids, Neues Jahrb. Geol. P.-A., 250, 31-44, doi:10.1127/0077-7749/2008/0250-0031, 2008.

Kruta, I., Landman, N., Rouget, I., Cecca, F., and Tafforeau, P.: The role of ammonites in the Mesozoic marine food web revealed by jaw preservation, Science, 331, 70-72, doi:10.1126/science.1198793, 2011.

Kruta, I., Landman, N., Rouget, I., Cecca, F., and Tafforeau, P.: The radula of the Late Cretaceous scaphitid ammonite Rhaeboceras halli (Meek and Hayden, 1856), Palaeontology, 56, 9-14, doi:10.1111/j.1475-4983.2012.01188.x, 2013.

Kruta, I., Landman, N. H., Mapes, R., and Pradel, A.: New insights into the buccal apparatus of the Goniatitina: palaeobiological and phylogenetic implications, Lethaia, 47, 38-48, doi:10.1111/let.12036, 2014.

Lehmann, W. M.: Stereo-Röntgenaufnahmen als Hilfsmittel bei der Untersuchung von Versteinerungen, Natur und Museum, 62, 323-330, 1932.

Luo, Z. and Ketten, D. R.: CT scanning and computerized reconstructions of the inner ear of multituberculate mammals, J. Vertebr. Paleontol., 11, 220-228, doi:10.1080/02724634.1991.10011389, 1991.

Marks II, R. J.: Introduction to Shannon sampling and interpolation theory, Springer-Verlag, New York, 324 pp., 1991.

Marshall, J. D.: Zoned calcites in Jurassic ammonite chambers: trace elements, isotopes and neomorphic origin, Sedimentology, 28, 867-887, doi:10.1111/j.1365-3091.1981.tb01949.x, 1981.

Mietchen, D., Keupp, H., Manz, B., and Volke, F.: Non-invasive diagnostics in fossils - Magnetic Resonance Imaging of pathological belemnites, Biogeosciences, 2, 133-140, doi:10.5194/bg2-133-2005, 2005.

Mietchen, D., Aberhan, M., Manz, B., Hampe, O., Mohr, B., Neumann, C., and Volke, F.: Three-dimensional Magnetic Resonance Imaging of fossils across taxa, Biogeosciences, 5, 25-41, doi:10.5194/bg-5-25-2008, 2008.

Monnet, C., Bucher, H., Wasmer, M., and Guex, J.: Revision of the genus Acrochordiceras Hyatt, 1877 (Ammonoidea, Middle Triassic): morphology, biometry, biostratigraphy and intra-specific variability, Palaeontology, 53, 961-996, doi:10.1111/j.14754983.2010.00956.x, 2010.

Mooney, T. A., Hanlon, R. T., Christensen-Dalsgaard, J., Madsen, P. T., Ketten, D. R., and Nachtigall, P. E.: Sound detection by the longfin squid (Loligo pealeii) studied with auditory evoked potentials: sensitivity to low-frequency particle motion and not pressure, J. Exp. Biol., 213, 3748-3759, doi:10.1242/jeb.048348, 2010.

Moreau, J.-D., Cloetens, P., Gomez, B., Daviero-Gomez, V., Néraudeau, D., Lafford, T. A., and Tafforeau, P.: Multiscale 3$\mathrm{D}$ virtual dissections of 100-million-year-old flowers using $\mathrm{x}$-ray synchrotron micro- and nanotomography, Microsc. Microanal., 20, 305-312, doi:10.1017/S1431927613014025, 2014.

Naglik, C., Monnet, C., Götz, S., Kolb, C., De Baets, K., Tajika, A., and Klug, C.: Growth trajectories of some major ammonoid subclades using grinding tomography data, Lethaia, accepted, 2014.

Pascual-Cebrian, E., Hennhöfer, D., and Götz, S.: 3-D morphometry of polyconitid rudist bivalves based on grinding tomography, Facies, 59, 347-358, doi:10.1007/s10347-012-0310-8, 2013.

Perrichot, V., Marion, L., Néraudeau, D., Vullo, R., and Tafforeau, P.: The early evolution of feathers: fossil evidence from Cretaceous amber of France, P. Roy. Soc. B-Biol. Sci., 275, $1197-$ 1202, doi:10.1098/rspb.2008.0003, 2008.

Pouech, J., Mazin, J.-M., and Tafforeau, P.: High quality 3-D imaging of vertebrate microremains using $\mathrm{X}$-ray synchrotron 
phase contrast microtomography, C. R. Palevol., 9, 389-395, doi:10.1016/j.crpv.2010.07.010, 2010.

Prymak, O., Tiemann, H., Sötje, I., Marxen, J., Klocke, A., KahlNieke, B., Beckmann, F., Donath, T., and Epple, M.: Application of synchrotron-radiation-based computer microtomography (SRICT) to selected biominerals: embryonic snails, statoliths of medusae, and human teeth, J. Biol. Inorg. Chem., 10, 688-695, doi:10.1007/s00775-005-0023-3, 2005.

Quast, M. J., Neumeister, H., Ezell, E. L., and Budelmann, B. U.: MR microscopy of cobalt-labeled nerve cells and pathways in an invertebrate brain (Sepia officinalis, Cephalopoda), Magn. Reson. Med., 45, 575-579, doi:10.1002/mrm.1078, 2001.

Rahman, I. A., Adcock, K., and Garwood, R. J.: Virtual fossils: a new resource for science communication in paleontology, Evo. Edu. Outreach, 5, 635-641, doi:10.1007/s12052-012-04582, 2012.

Rayfield, E. J.: Finite element analysis and understanding the biomechanics and evolution of living and fossil organisms, Annu. Rev. Earth Pl. Sc., 35, 541-576, doi:10.1146/annurev.earth.35.031306.140104, 2007.

Ritterbush, K. A., Hoffmann, R., Lukeneder, A., and De Baets, K.: Pelagic palaeoecology: the importance of recent constraints on ammonoid palaeobiology and life history, J. Zool., 292, 229-241, doi:10.1111/jzo.12118, 2014

Sanchez, S., Ahlberg, P. E., Trinajstic, K. M., Mirone, A., and Tafforeau, P.: Three-dimensional synchrotron virtual paleohistology: a new insight into the world of fossil bone microstructures, Microsc. Microanal., 18, 1095-1105, doi:10.1017/S1431927612001079, 2012.

Schindewolf, O. H.: Studien zur Stammesgeschichte der Ammoniten, Abh. Akad. Wiss. Lit. Mainz, Math.-Naturw. Kl., 19601968, 1-901, 1961-1968.

Schreiber, G. and Hoffmann, R.: Der Septallobus als diagnostisches Merkmal für die Überfamilie Lytoceratoidea (Cephalopoda: Ammonitina), Berliner Paläobiologische Abhandlungen, 10, 307310, 2009.

Shigeta, Y.: Post-hatching early life history of Cretaceous Ammonoidea, Lethaia, 26, 133-145, doi:10.1111/j.15023931.1993.tb01804.x, 1993.

Shiino, Y., Kuwazuru, O., Suzuki, Y., and Ono, S.: Swimming capability of the remopleuridid trilobite Hypodicranotus striatus: Hydrodynamic functions of the exoskeleton and the long, forked hypostome, J. Theor. Biol., 300, 29-38, doi:10.1016/j.jtbi.2012.01.012, 2012.

Sollas, I. B. J. and Sollas, W. J.: A study of the skull of a Dicynodon by means of serial sections, Philos. T. R. Soc. B, 204, 201-225, 1914.

Sollas, W. J.: A method for the investigation of fossils by serial sections, Philos. T. R. Soc. B, 196, 259-265, 1904.
Stock, S. R.: Microcomputed tomography - methodology and applications, CRC Press, Taylor \& Francis Group, Boca Raton, 331 pp., 2006.

Sutton, M. D., Briggs, D. E. G., Siveter, D. J., and Siveter, D. J.: Methodologies for the visualization and reconstruction of threedimensional fossils from the Silurian Herefordshire Lagerstätte, Palaeontol. Electron., 4, 1-17, 2001.

Sutton, M. D., Rahman, I. A., and Garwood, R. J.: Techniques for virtual palaeontology, Wiley-Blackwell, Chichester, 2014.

Tafforeau, P. and Smith, T.: Synchrotron virtual palaeohistology: accessing the archives of hominin dental development and life history non-destructively, 11th International Conference on Tooth Morphogenesis and Differentiation, 21, 2013.

Tafforeau, P., Boistel, R., Boller, E., Bravin, A., Brunet, M., Chaimanee, Y., Cloetens, P., Feist, M., Hoszowska, J., Jaeger, J.-J., Kay, R. F., Lazzari, V., Marivaux, L., Nel, A., Nemoz, C., Thibault, X., Vignaud, P., and Zabler, S.: Applications of Xray synchrotron microtomography for non-destructive 3-D studies of paleontological specimens, Appl. Phys. A, 83, 195-202, doi:10.1007/s00339-006-3507-2, 2006.

Tanabe, K., Misaki, A., Landman, N. H., and Kato, T.: The jaw apparatuses of Cretaceous Phylloceratina (Ammonoidea), Lethaia, 46, 399-408, doi:10.1111/let.12017, 2013.

Tipper, J. C.: The study of geological objects in three dimensions by the computerized reconstruction of serial sections, J. Geol., 84, 476-484, 1976.

Warnke, K. M. and Boletzky, S. V.: The "ventral rib" of the shell in Spirula (Cephalopoda, Coleoidea): a cryptic rostrum?, Berliner Paläobiologische Abhandlungen, 10, 357-359, 2009.

Weitschat, W.: Intraspecific variation of Svalbardiceras spitzbergensis (Frebold) from the Early Triassic (Spathian) of Spitsbergen, Polar Res., 27, 292-297, doi:10.1111/j.17518369.2008.00041.x, 2008.

Westermann, B., Ruth, P., Litzlbauer, H. D., Beck, I., Beuerlein, K., Schmidtberg, H., Kaleta, E. F., and Schipp, R.: The digestive tract of Nautilus pompilius (Cephalopoda, Tetrabranchiata): an X-ray analytical and computational tomography study on the living animal, J. Exp. Biol., 205, 1617-1624, 2002.

Westermann, G. E. G.: On alleged negative buoyancy of ammonoids, Lethaia, 26, 246, doi:10.1111/j.15023931.1993.tb01526.x, 1993.

Withers, P. J.: X-ray nanotomography, Mater. Today, 10, 26-34, doi:10.1016/S1369-7021(07)70305-X, 2007.

Ziegler, A., Kunth, M., Mueller, S., Bock, C., Pohmann, R., Schröder, L., Faber, C., and Giribet, G.: Application of magnetic resonance imaging in zoology, Zoomorphology, 130, 227-254, doi:10.1007/s00435-011-0138-8, 2011. 